\title{
Diversity and substrate-specificity of green algae and other micro-eukaryotes colonizing amphibian clutches in Germany, revealed by DNA metabarcoding
}

\author{
Sten Anslan ${ }^{1}$ - Maria Sachs ${ }^{2} \cdot$ Lois Rancilhac $^{1} \cdot$ Henner Brinkmann $^{3} \cdot$ Jörn Petersen $^{3} \cdot$ Sven Künzel $^{4} \cdot$ Anja Schwarz $^{5}$. \\ Hartmut Arndt $^{2} \cdot$ Ryan Kerney $^{6} \cdot$ Miguel Vences $^{1}$
}

Received: 17 November 2020 / Revised: 20 March 2021 / Accepted: 2 May 2021 / Published online: 28 June 2021

(c) The Author(s) 2021

\begin{abstract}
Amphibian clutches are colonized by diverse but poorly studied communities of micro-organisms. One of the most noted ones is the unicellular green alga, Oophila amblystomatis, but the occurrence and role of other micro-organisms in the capsular chamber surrounding amphibian clutches have remained largely unstudied. Here, we undertook a multi-marker DNA metabarcoding study to characterize the community of algae and other micro-eukaryotes associated with agile frog (Rana dalmatina) clutches. Samplings were performed at three small ponds in Germany, from four substrates: water, sediment, tree leaves from the bottom of the pond, and $R$. dalmatina clutches. Sampling substrate strongly determined the community compositions of algae and other micro-eukaryotes. Therefore, as expected, the frog clutch-associated communities formed clearly distinct clusters. Clutch-associated communities in our study were structured by a plethora of not only green algae, but also diatoms and other ochrophytes. The most abundant operational taxonomic units (OTUs) in clutch samples were taxa from Chlamydomonas, Oophila, but also from Nitzschia and other ochrophytes. Sequences of Oophila "Clade B" were found exclusively in clutches. Based on additional phylogenetic analyses of $18 \mathrm{~S}$ rDNA and of a matrix of 18 nuclear genes derived from transcriptomes, we confirmed in our samples the existence of two distinct clades of green algae assigned to Oophila in past studies. We hypothesize that "Clade B" algae correspond to the true Oophila, whereas "Clade A" algae are a series of Chlorococcum species that, along with other green algae, ochrophytes and protists, colonize amphibian clutches opportunistically and are often cultured from clutch samples due to their robust growth performance. The clutch-associated communities were subject to filtering by sampling location, suggesting that the taxa colonizing amphibian clutches can drastically differ depending on environmental conditions.
\end{abstract}

Keywords DNA metabarcoding $\cdot$ Symbiosis $\cdot$ Oophila $\cdot$ Rana dalmatina $\cdot$ Amphibians $\cdot$ Algae

Communicated by: Oliver Hawlitschek

Sten Anslan

s.anslan@tu-braunschweig.de

1 Zoological Institute, Technische Universität Braunschweig, Braunschweig, Germany

2 Institute of Zoology, University of Cologne, Zülpicherstr. 47b, 50674 Köln, Germany

3 Leibniz Institute DSMZ - German Collection of Microorganisms and Cell Cultures, Inhoffenstraße 7B, 38124 Braunschweig, Germany
4 Department of Evolutionary Genetics, Max Planck Institute for Evolutionary Biology, 24306 Plön, Germany

5 Institute of Geosystems and Bioindication, Technische Universität Braunschweig, Braunschweig, Germany

6 Department of Biology, Gettysburg College, Gettysburg, PA, USA 


\section{Introduction}

Amphibians are characterized by a striking diversity of reproductive modes (Haddad and Prado 2005; Salthe and Duellman 1973) that also is reflected in the diversity of eggs and clutches they deposit (Altig and McDiarmid 2007). Amphibian eggs are typically surrounded by a vitelline membrane and several egg capsule layers suspended in a jelly matrix consisting of mucopolysaccharides secreted by the oviduct (Salthe 1963). In many cases, single eggs with their surrounding jelly layers are combined into complex clutches, strings, or sacs. Studies on water molds (Johnson et al. 2008; Petrisko et al. 2008), bacterial (Hughey et al. 2017), and micro-eukaryotic organisms (Jurga et al. 2020) suggest that amphibian eggs are colonized by diverse but poorly studied communities of prokaryotic and eukaryotic organisms, some of which may be specifically adapted to this micro-ecosystem.

One of the most prominent organisms associated with amphibian eggs is the unicellular green alga, Oophila amblystomatis. This alga is characterized by a close and mutualistic association with amphibian eggs and embryos from multiple species. The singular interactions of Oophila with its amphibian hosts, in particular with North American salamanders of the genus Ambystoma, were noted as early as in the late nineteenth century (Orr 1888). In these salamanders, the embryo exits the vitelline membrane during neurulation (see Altig and McDiarmid 2007; Salthe 1963 for details of egg capsule structure), and a bloom of $O$. amblystomatis proliferates outside the embryonic blastopore. Oophila within the capsular chamber provide an increase in the partial pressure of oxygen during the day, potentially remove nitrogenous waste, and have been reported to transfer photosynthate to the amphibian embryos (Bachmann et al. 1986; Goff and Stein 1978; Graham et al. 2013; Kerney 2011; Pinder and Friet 1994), which may lead to acceleration of embryonal development, larger sized embryos, increased viability and hatching success (Gilbert 1942, 1944). However, other studies have reported no measurable exchange of photosynthate from algae to amphibian embryos (Burns et al. 2020). Additional effects by the algae, such as a reduction of micro-organisms that are potentially harmful to the host, have been hypothesized (Kim et al. 2014) but not yet tested. Potential benefits for the algae are less studied. It is suggested that the capsular chamber of amphibian eggs provides a protective environment, acts as an insulator, and thereby offers higher temperatures than the pond water (Beattie 1980). Additionally, it has been argued that the host embryos may provide nitrogenous compounds to algae (Goff and Stein 1978), yet this hypothesis remains controversial (Bianchini et al. 2012; Small et al. 2014). The close symbiotic association of Oophila with its amphibian hosts even leads to algal cells invading host embryonic tissues and cells in the spotted salamander
(Ambystoma maculatum), and thus constitutes a unique example of endosymbiosis in vertebrates (Kerney et al. 2011, 2019).

Despite the considerable amount of research carried out on Oophila, numerous aspects of this mutualistic amphibianalgae system remain insufficiently studied. These include even fundamental questions such as the taxonomic identity and global distribution of these amphibian-associated algae, host specificity, and ecology of the algae outside of the amphibian breeding season. Molecular work based on algal cultures isolated from amphibian clutches (Kim et al. 2014; Muto et al. 2017) and DNA metabarcoding (Jurga et al. 2020) found almost all DNA sequences belonging to one clade of green algae. This clade had a somewhat isolated (phylogenetic) position within Chlamydomonadales, and besides, the clutch-associated algae contained only three isolates of free-living algae. Isolates of this clade have been consistently considered as $O$. amblystomatis, which is regarded as the numerically most abundant alga in $\mathrm{A}$. $\mathrm{macu}$ latum (Jurga et al. 2020) and A. gracile (Kerney et al. 2019; Marco and Blaustein 2000) egg capsule chambers. These $O$. amblystomatis isolates have been used in studies of gene expression (Burns et al. 2017; Kerney et al. 2019), carbon fixation (Burns et al. 2020), and host-symbiont fidelity (Kerney et al. 2019). As an exception, a few isolates from $A$. maculatum egg masses, along with environmental samples, were assigned to Chlamydomonas gloeophila; however, $C$. gloeophila was suggested to represent low abundance green algae occurring in these egg masses that outcompeted Oophila under agar media growth conditions in culture (Kim et al. 2014).

A recent study by Nema et al. (2019), in contrast, found algae isolated from amphibian clutches to be phylogenetically diverse. They considered their new isolates from near the type locality as Oophila "Clade A", purportedly representing the true $O$. amblystomatis, and referred to the previously studied algae as Oophila "Clade B". This interpretation is based on molecular sampling done in another unpublished study (Lewis and Landberg 2014) and the unpublished naming of $O$. amblystomatis by Lambert (Printz 1927) from samples collected outside of Boston, MA. Because "Clade A" sequences are closely related to species of Chlorococcum, Correia et al. (2020), relying on the taxonomic conclusion of Nema et al. (2019) suggested to re-name the species as Chlorococcum amblystomatis. While a conclusive taxonomic decision on the identity of Oophila will require more in-depth study of the (preserved) material used for the original description of the taxon, some hints on the conundrum can be also obtained by better understanding the ecology of these algae. In particular, by addressing the following topics, it might be possible to distinguish between actual amphibian clutch symbionts (very likely corresponding to those algae originally described as Oophila) and opportunistic generalists that occur in low abundances 
in this habitat but may be more easily cultured: (i) assessing which alga is numerically most abundant in amphibian clutches, (ii) under which ecological conditions and in which developmental stage different algae and other microorganisms may opportunistically invade these clutches, and (iii) whether specific culturing conditions may favor lowabundance algae relative to the strains of Oophila "Clade B".

Besides green algae, the occurrence and role of other micro-organisms in the capsular chamber surrounding amphibian eggs, and in amphibian clutches in general, also remain mostly unstudied. Bacterial communities associated with frog clutches are similar to those on the skin of adult frogs (Hughey et al. 2017). As the cutaneous microbiome in amphibians provides an important defense line against pathogenic fungi (Bletz et al. 2013), it may be speculated that clutch-associated bacterial microbiome may represent an extended component of the embryo's pathogen defense. Recent studies have also shown that one of the most important amphibian pathogens, the chytrid fungus Batrachochytrium dendrobatidis that has caused dramatic amphibian declines globally (Fisher and Garner 2020) is mitigated by the presence of micro-eukaryotes predating on its zoospores (Schmeller et al. 2014). Protozoan micro-predators (Yassin and El-Said 2011) and probiotic bacteria (Chauhan and Singh 2019) have also proven effective in reducing the growth of Saprolegnia water molds that are known to cause extended mortality of amphibian eggs (Blaustein et al. 1994; Gomez-Mestre et al. 2006). Recently, Jurga et al. (2020) used a DNA metabarcoding approach to demonstrate that fluid from the capsular chambers of A. maculatum clutches contained communities of micro-eukaryotes that represented a subset of the aquatic taxa present in free water at the respective sampling sites. Besides Oophila, also cercozoan protists and chytrid fungi were sometimes abundant. Given the diversity of the jelly layer structure in different amphibians with differences sometimes detected even in the same species (Beattie 1980) and the variation of microbes depending on habitat properties (Bock et al. 2020; Montiel et al. 2019), substantial differences can be expected in the communities of organisms inhabiting the amphibian clutch micro-environment.

Driven by our own field observations in Germany suggesting regular occurrence of micro-algae in the capsular egg chambers in clutches of agile frogs, Rana dalmatina, we undertook a multi-marker DNA metabarcoding study to better characterize the community of algae and other micro-eukaryotes associated with these clutches. To assess the occurrence and taxonomic identity of micro-organisms associated with $R$. dalmatina clutches, we pursued three main research questions: (i) Which species and strains of algae occur in clutches of $R$. dalmatina (in Germany) and how are these related to the strains identified from North America and Japan? (ii) Do Oophila and other amphibian clutch-associated algae occur also elsewhere in the pond environment? (iii) Lastly, what are the evolutionary relationships of algae isolated from amphibian clutches to other Chlorophyta? This final question required combining sequences derived from transcriptomes and DNA metabarcoding, along with the sequences from previous studies, for taxonomic and phylogenetic analyses.

\section{Methods}

\section{Sampling}

Sampling was performed at three small ponds in Germany, all located in the Elm region near Braunschweig, here named Lelm1, Lelm2, and Dahlum (Online Resource 1, Table S1; Fig. 1a). Samples were collected from four types of substrates: (1) water, (2) sediment, (3) tree leaves from the bottom of the pond, and (4) R. dalmatina clutches (Fig. 1b). Water samples were collected via an algal net $(0.25 \mu \mathrm{m}$ mesh) by filtering and concentrating water into the $100 \mathrm{ml}$ collection bottle (scooping the algal net in the center of the pond eight times across ca. $3 \mathrm{~m}$ ). Sediment samples were collected from six random locations from the bottom of the pond by collecting a total of ca. $450 \mathrm{~g}$ from the top $2 \mathrm{~cm}$ layer. Nine tree leaves (elm or oak) were collected per pond at random locations into the $50 \mathrm{ml}$ sterile tubes. When the frog clutches emerged at the ponds at random location, jelly samples from approximately 30 eggs were collected for $R$. dalmatina by placing the samples into a sterile $50 \mathrm{ml}$ tube, after photographing the clutch to determine developmental stage. The first sampling of clutches was performed on the $25^{\text {th }}$ of March 2019 and the last on the $18^{\text {th }}$ of April 2019 (Lelm 1 and Lelm2) and $11^{\text {th }}$ of April 2019 (in Dahlum sampling site, i.e., no clutches in Dahlum on $18^{\text {th }}$ of April 2019). Total number of collected samples was 100; 24 for water, sediment and leaf samples and 28 for clutch samples (Online Resource 1, Table S1). All samples, except clutches, were frozen at $-20{ }^{\circ} \mathrm{C}$ (maximum of $2 \mathrm{~h}$ after collection) until further processing.

The algal colonization rate and embryo developmental stage were recorded for $R$. dalmatina clutch samples (Online Resource 1, Table S1; Fig. 1c-d). Embryo developmental stages were categorized to (i) egg to very early embryo, i.e., approximately corresponding to stages 1-14 according to the classification of Gosner (1960); (ii) early to moderately developed embryo, larval form not yet fully developed, approximate Gosner stages 15-19; (iii) hatchling with external gills but still inside egg, approximate Gosner stages 20-22; (iv) hatched embryo, approximate Gosner stages over 22. In the laboratory, clutch samples in $50 \mathrm{ml}$ tubes were immediately poured onto Petri dishes, where ca. $4 \mathrm{ml}$ of the clutches mass (without embryos) 
Fig. 1 Clutches and eggs of Rana dalmatina from sampled ponds with unicellular green algae in the capsular chamber. (a) Pond "Lelm1" in early spring after the main spawning event. (b) Male Rana dalmatina with a green-colored clutch due to development of green algae within this egg mass. (c, f) Close-up images of early tadpole stages and remains of egg clutches with green algae in the inner egg capsule. Non-motile zygotes (d) and a flagellated zoospore (e) of these algae
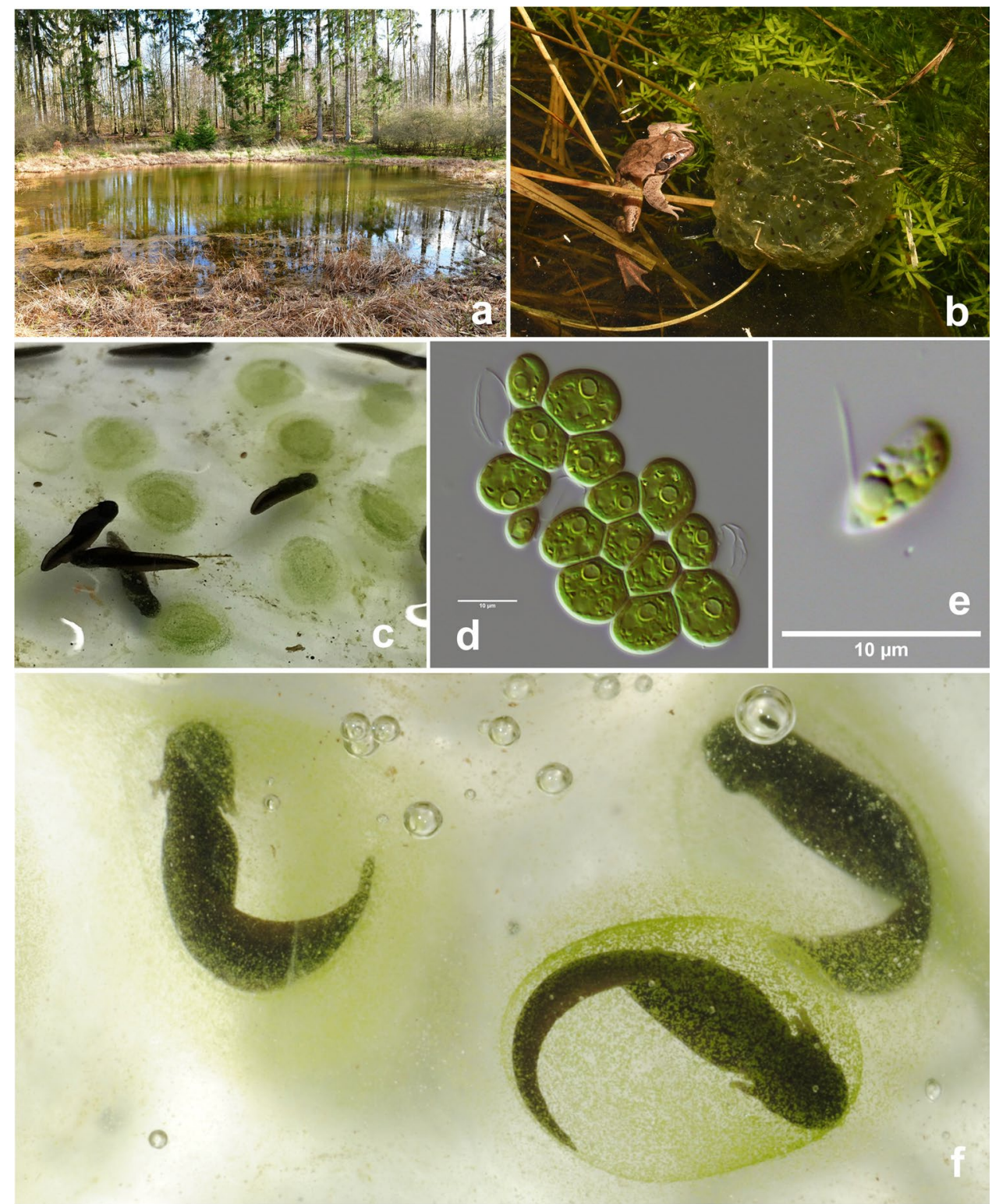

were transferred (with sterile $2 \mathrm{ml}$ syringes) to new sterile $50 \mathrm{ml}$ tubes avoiding the obvious outer 'environmental contamination' as much as possible. About $20 \mathrm{ml}$ of RNA later solution was added on top of each $4 \mathrm{ml}$ clutch sample, briefly vortexed, and stored at $4{ }^{\circ} \mathrm{C}$. Detailed sample preparation for DNA extractions is described in Online Resource 2 (extended methods). Because only jelly samples of the clutches were collected and no larval or metamorphosed vertebrates were manipulated, ethics approval for our study was not required. Permission to handle amphibians in the study ponds was granted by the Untere Naturschutzbehörde of the Landkreis Helmstedt (16/605,105-269/14 and 16/605,105-074/21).

\section{Molecular analyses}

All DNA extractions were performed using DNeasy PowerSoil Kit (Qiagen, Germany) following the manufacturer's instructions. PCRs were performed using uniquely tagged primers $(8 \mathrm{bp}+2-4$ bp heterogeneity spaces; Online Resource 1, Table S2) for amplifying fragments of RuBisCO large subunit (rbcL) and eukaryotic small subunit of ribosomal RNA (18S SSU rRNA). For amplifying the rbcL region, we used the newly designed primers, rbcL$646 \mathrm{Fcl}\left(5^{\prime}\right.$-ATG CGT TGG MGW GAY CGT TTC-3') and rbcL-998Rcl (5'-GTT CHC CTT CWA RTT TWC CWA CWA C-3'), modified from Kelly et al. (2018; rbcL646F 
and rbcL998R, designed for diatoms) to amplify a wider range of photosynthetic micro-algae (targeting especially Chlamydomonadales). These new rbcL primers amplify a fragment of 333-336 bp. For amplifying 18S (V9 region), we used universal primers Euk1391f (5'-GTA CAC ACC GCC CGT C-3') and EukBr (5'-TGA TCC TTC TGC AGG TTC ACC TAC-3') (Amaral-Zettler et al. 2009; Stoeck et al. 2010). PCR mix, $25 \mu \mathrm{l}$ per sample, consisted of $5 \mu \mathrm{l}$ of Hot Start FirePol Master Mix (Solis BioDyne, Estonia), $0.5 \mu \mathrm{l}$ forward and reverse primers $(10 \mu \mathrm{M}), 1 \mu \mathrm{l}$ of template DNA, and $18 \mu \mathrm{l}$ of nuclease-free water. PCR conditions for rbcL included initial hot-start at $95{ }^{\circ} \mathrm{C}$ for $15 \mathrm{~min}$, following 35 cycles of $95{ }^{\circ} \mathrm{C}$ for $30 \mathrm{~s}, 55^{\circ} \mathrm{C}$ for $45 \mathrm{~s}, 72{ }^{\circ} \mathrm{C}$ for $1 \mathrm{~min}$, and final extension at $72{ }^{\circ} \mathrm{C}$ for $10 \mathrm{~min}$. PCR conditions for $18 \mathrm{~S}$ included initial hot-start at $95{ }^{\circ} \mathrm{C}$ for $15 \mathrm{~min}$, following 35 cycles of $94{ }^{\circ} \mathrm{C}$ for $45 \mathrm{~s}, 57^{\circ} \mathrm{C}$ for $1 \mathrm{~min}, 72^{\circ} \mathrm{C}$ for $1 \mathrm{~min}$ $90 \mathrm{~s}$, and final extension at $72{ }^{\circ} \mathrm{C}$ for $10 \mathrm{~min}$. Two replicate PCRs were performed per sample. Sample replicates were pooled, and the yield of PCR products were checked via gel electrophoresis by pipetting $5 \mu \mathrm{lPCR}$ product on $1 \%$ agarose gel. All PCR products were pooled based on their relative quantity (as observed on the gel) and purified using FavorPrep $^{\mathrm{TM}}$ Gel/PCR Purification Kit (Favorgen-Biotech Corp., Austria), following the manufacturer's instructions. Steps of DNA extraction, PCR, and sequencing included both negative and positive controls. Negative controls included blank DNA extractions and also PCRs with no-template DNA. DNA extracts from cultured species of diatoms were used as a positive control to monitor the functionality of PCRs and sequencing. Additionally, sixteen 'un-used tag' control samples were used (Online Resource 1, Table S2) to account for potential 'tag-switching' errors (Taberlet et al. 2018). All molecular procedures were performed under a laminar flow clean bench, with $30 \mathrm{~min}$ UV sterilization prior to and after each step. Sequencing was performed on an Illumina MiSeq instrument using MiSeq Reagent Kit v2 $(2 \times 250)$. Illumina sequencing data sets have been deposited in the Sequence Read Archive (SRA), BioProject ID: PRJNA714784.

\section{Bioinformatics}

Raw paired-end Illumina sequencing data were processed in the PipeCraft platform (Anslan et al. 2017), which included merging paired-end reads, quality filtering, chimera filtering, clustering, and formation of operational taxonomic units (OTUs) tables for both (rbcL and 18S) genes. Paired-end reads merging and quality filtering were processed using vsearch (Rognes et al. 2016); maximum expected error threshold of 1 (-fastq_maxee $=1$ ) and discarding sequences with ambiguous bases (-fastq_maxns $=0$ ). Putative chimeric reads were filtered using the uchime_denovo algorithm in vsearch (default settings). Few additional reads where a fulllength primer string was detected inside the sequence (i.e., 'multiprimer artefacts') were discarded using the PipeCraft built-in module ('remove primer artefacts'). Clustering of the sequences was performed using the UPARSE algorithm (Edgar 2013) with a 97\% sequence similarity threshold. For taxonomy assignment, representative sequences (UPARSE centroids) for each OTU were compared against the EMBL v142 (Kanz et al. 2005) reference database using the blastn algorithm (Camacho et al. 2009). Based on the control samples and blastn results, the OTU tables were further checked and filtered to remove potential contaminants and mitigate tag-switching errors. Detailed OTU table curation is described in Online Resource 2 (extended methods).

\section{Statistics}

Permutational Analysis of Variance (PERMANOVA, with 9999 permutations) was used for detecting the effects of substrate (water, leaves, sediments, clutches), sampling site (Lelm1, Lelm2, Dahlum), and sampling date (8 sampling dates) on the OTU community composition using PRIMER v6 (Clarke and Gorley 2006). Log-transformed Bray-Curtis as well as UniFrac distance (unweighted) OTU matrices were used for the PERMANOVA analyses. UniFrac distances were calculated using the PhyloMeasures package (Tsirogiannis and Sandel 2016) in R (v3.6.2; R-Core-Team 2019) using Maximum-likelihood based phylogenetic rbcL and 18S amplicon trees generated with RAxML (Stamatakis 2014) under the GTRGAMMA model. Because sequencing depth may affect the OTU abundance (thus, community composition patterns), sequence counts per sample were used as a covariate (Type I SS). Obvious outliers were screened with non-metric multidimensional scaling (NMDS) analyses and removed prior to PERMANOVA. Distancebased linear model (DistLM) with forward selection procedure and AICc selection criterion (using PRIMER v6) was used to detect the most important factors affecting the algal (rbcL data) and micro-eukaryotic (18S data) communities associated with frog clutch samples (9999 permutations). For identifying OTUs that are consistently present in a given substrate type (i.e., indicator OTUs), indicator species analyses were performed using the 'indicspecies' library (De Caceres et al. 2016) in R. Interactive visualization graphs for indicator OTUs (taxa) were generated using a Krona chart (Ondov et al. 2011). Bar plots for taxonomic distributions were generated using the 'phyloseq' package (McMurdie and Holmes 2013) in R. Temporal distance decay of similarity of OTU composition was explored by Mantel tests using the 'vegan' package (Oksanen et al. 2015) in R.

\section{Culturing, Sanger sequencing and RNAseq}

Single $R$. dalmatina egg envelopes were cut open with microsurgery scissors, and algal cells were extracted with a 
micromanipulator (Patchman NP2, Eppendorf, Germany). The obtained algal cells were cultivated in Waris $\mathrm{H}$ medium (McFadden and Melkonian 1986) under standard conditions (light/dark $14: 10 \mathrm{~h}$ at $16{ }^{\circ} \mathrm{C}$ and $5000 \mathrm{~K}$ provided by LED daylight strips, SunLike Linear Z 560-52, Lumitronix, Germany). For DNA extraction, the culture was centrifuged at $4000 \times \mathrm{g}$ for $20 \mathrm{~min}$ at $4{ }^{\circ} \mathrm{C}$. The pellet was re-suspended in $700 \mu \mathrm{l}$ Genomic Lysis Buffer using the Quick DNA prep kit (Zymo Research, USA) following the manufacturer's protocol for cell suspensions. The complete $18 \mathrm{~S}$ rDNA was amplified in PCR reactions using $1.5 \mu \mathrm{l}$ genomic DNA template, $12.5 \mu$ l Red Taq Polymerase Master Mix (VWR Chemicals International, Belgium), and each $2.5 \mu \mathrm{l} 18 \mathrm{~S}$ for 5'-AAC CTG GTT GAT CCT GCC AGT-3' and 18S-Rev 5'-TGA TCC TTC CGC AGG TTC ACC TAC-3' primer (Medlin et al. 1988). The thermal amplification program followed Schoenle et al. (2019): initial denaturation at $98^{\circ} \mathrm{C}$ for 2 min, followed by 35 cycles of $30 \mathrm{~s}$ at $98{ }^{\circ} \mathrm{C}, 45 \mathrm{~s}$ at $55^{\circ} \mathrm{C}$ and $2 \mathrm{~min} 30 \mathrm{~s}$ for $72^{\circ} \mathrm{C}$, and ending with a final elongation step of $72{ }^{\circ} \mathrm{C}$ for $10 \mathrm{~min}$. PCR products were purified using the PCR purification kit (Jena Bioscience, Germany) following the manufacturer's protocol and sequenced with the corresponding amplification primers at GATC Biotech Cologne. Sequence editing and quality check were performed using the Bioedit Sequence Alignment Editor (v7.2.6; Hall 1999). The 18S sequence (isolate MVRNA93) has been deposited in Genbank (Benson et al. 2013), under accession number MW723501.

For RNA extraction, a sample of ca. $100 \mathrm{mg}$ of the culture was preserved in RNAlater at $-80^{\circ} \mathrm{C}$. Details about RNA extraction are described in Online Resource 2 (extended methods). Sequencing was carried out with a High Output $2 \times 150$ cycle kit on an Illumina NextSeq instrument. Reads were quality-trimmed and filtered using Trimmomatic v. 0.32 (Bolger et al. 2014) with default settings (i.e., slidingwindow: 4:5, leading: 5, trailing: 5, minlength: 25 ). Filtered reads were used for de novo transcriptome assembly using Trinity v. 2.1.0 (Grabherr et al. 2011) following a published protocol (Haas et al. 2013). Illumina NextSeq sequencing data is deposited in the SRA, BioProject ID: PRJNA712983.

\section{Phylogenetics}

For phylogenetic analyses, we relied mainly on sequences of the 18S rRNA gene because most previous studies focusing on Oophila used this gene, and numerous comparative sequences are therefore available. Analyses were performed at levels of taxonomy and sequence length to make the best use of all available data, and considering that fully combining all sequences is not feasible due to extremely different sequence lengths and sequence variation. Furthermore, we compiled multi-gene datasets from transcriptomic data containing 18 nuclear protein-coding genes. All alignments have been uploaded to Figshare (https://doi.org/10.6084/m9.figsh are.14216588).

A detailed structure of the data sets (Dataset 1-5) for phylogenetics is described in Online Resource 2 (extended methods). Briefly:

\section{Dataset 1}

To understand the identity and overall placement of the various algal isolates sequenced from amphibian clutches, we assembled a data set of all 18S rRNA sequences of such algae from Genbank (Benson et al. 2013), plus a comparative selection of Chlorophyta comprising (i) all outgroups and comparative sequences used in previous publications (Correia et al. 2020; Kim et al. 2014; Muto et al. 2017; Nema et al. 2019); (ii) all sequences assigned to Oophila in these studies and otherwise available from Genbank; (iii) all sequences with $>98 \%$ sequence identity and $>80 \%$ sequence coverage obtained via BLAST searches in the Genbank nucleotide collection, using the most complete $18 \mathrm{~S}$ sequences of Oophila "Clade A" and "Clade B" as queries, and (iv) a selection of sequences obtained via metabarcoding.

\section{Dataset 2}

To visualize the placement of additional Chlorophyta OTUs found by metabarcoding in different parts of the green algae tree, we used the initial full alignment from Dataset 1 but trimmed the $18 \mathrm{~S}$ sequences to $139 \mathrm{bp}$ to match the metabarcoding fragment.

\section{Dataset 3}

To better visualize the variation of sequences assigned to Oophila "Clade A" and "Clade B" relative to other related algae, we used the $18 \mathrm{~S}$ sequences from Dataset 1 as a basis and selected those taxa that either (i) were classified as Oophila, (ii) were classified as Chlorococcum and by Dataset 1 analysis were placed in a clade with sequences classified as Oophila, and (iii) were nested within the Oophila and Chlorococcum clades, or were direct sister taxa to samples classified as Oophila.

\section{Datasets 4 and 5}

To obtain confirmation of algae's placement isolated from amphibian clutches in two very distinct branches of the Chlorophyta from a genome-wide selection of markers, we used a recently published phylotranscriptomic data set across green plants (Leebens-Mack et al. 2019). For Dataset 4 , we downloaded the nucleotide alignments of 386 singlecopy nuclear genes used in the study by Leebens-Mack et al. 
(2019), and kept sequences of 115 Chlorophyta, plus four Streptophyta as outgroups. We then used the newly obtained transcriptome assembly from an algal isolate cultured from German clutches of $R$. dalmatina (MVRNA93), and an assembly of North American Oophila (reads available from SRA under SRR5445904) from a cultured isolate from the work of Burns et al. (2017). These two transcriptomes corresponded to Oophila "Clade A" and "Clade B" of Nema et al. (2019), respectively. We selected 18 genes (Online Resource 1, Table S7) with matches in both transcriptomes, added the respective new transcriptome sequences to the original alignments, and performed codon-based Clustal W alignments in MEGA7 (Kumar et al. 2016). After initial exploratory phylogenetic analyses at the nucleotide level, the alignments were translated to amino acids, yielding a total alignment length of 6758 amino acid (aa) positions for 121 taxa. To improve the analytical power for relationships within or target group (by including additional positions that were difficult to align for more distantly related algae), we ran a second analysis with the same settings for a reduced dataset (Dataset 5) with all taxa from a well-supported clade containing all taxa from Dataset 4 belonging to Chlamydomonadales, Sphaeropleales, Chaetophorales, Oedogoniales, and Chaetopeltidales, as well as representative outgroups (Online Resource 2). The final alignments contained 4219 aa (Dataset 4) and 4892 aa (Dataset 5).

\section{Dataset 6}

We also assessed the phylogenetic placement of amphibian clutch-associated algae using sequences of the rbcL marker. For this, we first extracted rbcL sequences from the two transcriptomes (MVRNA93 and SRR5445904), then retrieved all rbcL sequences of Oophila and Chlorococcum from
Genbank, plus sequences matching our transcriptome rbcL sequences with 87\% (SRR5445904) and 90\% (MVRNA93) identity in BLAST searches. To these sequences, we added the metabarcoding rbcL fragments of Oophila "Clade B" plus a series of additional algae clearly and in high read numbers associated to $R$. dalmatina clutches.

\section{Results}

Overall, DNA metabarcoding resulted in $663 \mathrm{rbcL}$ and 448 18 S OTUs (97,724 and 19,130 reads, respectively) across all substrates (water, leaves, sediments, clutches). Water, leaf, and sediment samples contained 351, 383, and $266 \mathrm{rbcL}$ OTUs, and 71, 188, and 133 18S OTUs, respectively. Clutch samples harbored $306 \mathrm{rbcL}$ and 195 18S OTUs. The proportion of these OTUs found exclusively in clutch samples was $16.3 \%$ (50 OTUs) and 56.9\% (111 OTUs) for rbcL and $18 \mathrm{~S}$ data, respectively (Fig. 2; Online Resource 1, Table S3). In addition to green algae assigned to Chlorophyta (89\% of reads), rbcL OTUs also included taxa from diatoms (Bacillariophyceae; $7.8 \%$ ) and other Ochrophyta (3.1\%) in the clutch samples (Fig. 3a). The relative abundance of $18 \mathrm{~S}$ reads associated with clutch samples was $40.6 \%$ for Chlorophyta, 26\% for non-diatom Ochrophyta, and 9.5\% for diatoms. Besides the latter, clutch samples contained taxa from Alveolata (12.1\% of reads), Fungi (7.7\%), and Oomycota (1.9\%) in the $18 \mathrm{~S}$ data set (Fig. 3d). Most frequently detected and most abundant (sequence read abundance) OTUs in the clutch samples were taxa from Chlamydomonas, Nitzschia, and Oophila as suggested by the rbcL metabarcoding data (Fig. 3b, c; Online Resource 1, Table S3), but also taxa from Alveolata and non-diatom Ochrophyta as indicated by the
Fig. 2 Venn diagram illustrating the distribution of operational taxonomic units (OTUs) across sampling substrates. Fifty rbcL and 11118 S OTUs were found exclusively in Rana dalmatina clutch samples. The list of OTUs is included in Online Resource 5
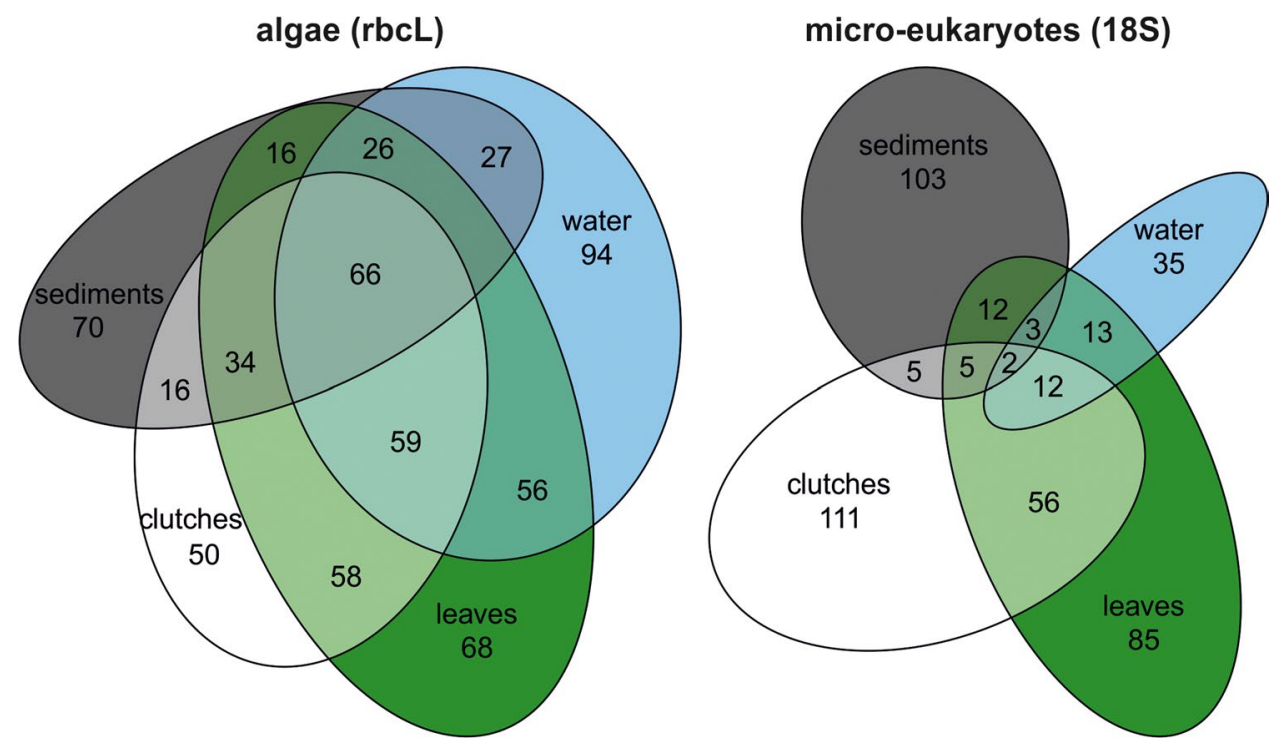

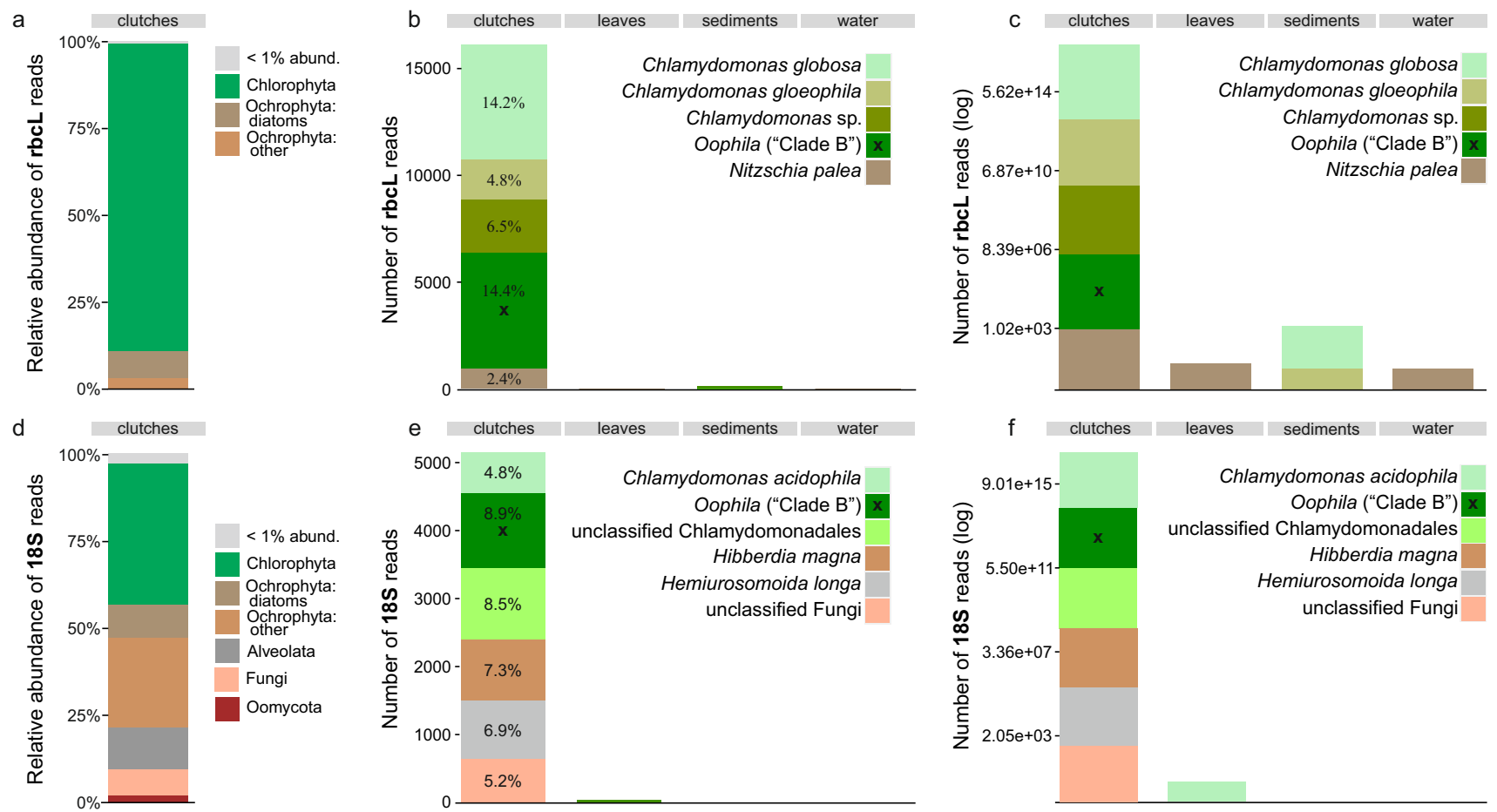

Fig. 3 Relative abundance of rbcL (a) and 18S (d) reads from taxa associated with clutch samples (relative abundance of reads from taxa associated with other substrates in Online Resource 4, Fig. S1). Bar plots for most abundant (sequence abundance) indicator rbcL $(\mathbf{b}, \mathbf{c})$ and $18 \mathrm{~S}(\mathbf{e}, \mathbf{f})$ operational taxonomic units (OTUs) detected in clutch samples (from Table 1). The y-axis of plots a and c repre-

18S data (Fig. 3e, f; Online Resource 1, Table S3) that were infrequent in other environmental samples (Table 1).

PERMANOVA analyses revealed significant effects of substrate, sampling site, and sampling date for both algal (rbcL) and micro-eukaryotic (18S) communities (Table 2; Fig. 4). The highest proportion of variance was explained by the substrate (Table 2), followed by the sampling site for algal (rbcL) communities, but by sampling date for microeukaryotic (18S) communities (Table 2).

Based on DistLM analysis, the best predictors for algal (rbcL) communities associated with the clutch samples were sampling site and embryo developmental stage category using the Bray-Curtis similarity matrix, but sampling site and sampling date for the UniFrac distance matrix (Online Resource 1, Table S4, Fig. 5). Sampling date, however, correlates significantly with embryo developmental stage (Spearman $\mathrm{R}>0.950, P<0.015$ for all ponds) and water temperature (Spearman $R>0.890, P<0.007$; Online Resource 4, Fig. S2). Best predictors for micro-eukaryotic (18S) communities associated with the clutch samples were also sampling site and embryo developmental stage, but additionally, sampling date was an important predictor in the analyses with Bray-Curtis similarity matrix (Online sent sequence counts, while these counts have been log transformed in $\mathrm{b}$ and $\mathrm{d}$ plots to better highlight the distribution of these OTUs in leaves, sediment, and water samples. For easier interpretation of the graph, the main target taxon (Oophila) is marked with $\mathrm{x}$ in the respective bars. Percentages in plots $\mathrm{b}$ and e represent the relative abundance of sequences for a corresponding taxon in the clutch samples

Resource 1, Table S4; Fig. 5). Pairwise analyses between sampling site and substrate showed that clutch samples differed between all sites for both algal and micro-eukaryotic communities $(P<0.033$ for all cases, except for $18 \mathrm{~S}$ UniFrac data set between sites of Lelm1 and Lelm2; Online Resource 1, Table S5). Also, algal and micro-eukaryotic communities from other substrates (water, leaves, sediments) varied significantly among sampling sites (Online Resource 1, Table S5).

Indicator species analyses (samples not separated by site) identified 22 algal (rbcL) and 30 micro-eukaryotic (18S) OTUs that were characteristic for $R$. dalmatina clutch samples (Online Resource 3; interactive Krona chatrs in Online Resource 4, Figs. S3, S4). OTUs assigned to Chlamydomonadaceae (Chlamydomonas sp., Oophila sp., Chloromonas sp.) accounted for $64 \%$ (14 OTUs) and $20 \%$ (6 OTUs) of indicator taxa in the rbcL and $18 \mathrm{~S}$ data sets, respectively. Other indicator taxa for clutch samples included OTUs assigned to other Chlamydomonadales (18\%, 4 OTUs) and Bacillariophyceae (diatoms; 18\%, 4 OTUs) in the rbcL data set (Online Resource 4, Fig. S3); and other Chlamydomonadales (10\%, 3 OTUs), Chlorosarcinaceae (3\%, 1 OTU), Bacillariophyceae (13\%, 4 OTUs), 
Table 1 The ten most frequently occurring and abundant (sequence abundance) rbcL and $18 \mathrm{~S}$ OTUs in Rana dalmatina clutch samples. Note that the marked taxa in the table represent blastn first match where the percentage in between parentheses denote the blastn identity percentage to noted taxa. Asterisks (*) indicate that the OTU was identified as an indicator OTU for clutch samples. An OTU with double asterisk $(* *)$ was identified as an indicator OTU for clutch + leaf samples (see Online Resource 3 for all indicator OTUs). Frequency denotes the occurrence number of the OTU across clutches samples (total $=28$ samples). Rel. abund. denotes relative abundance of sequences of the given OTU in clutches samples. Specificity and sensitivity (range $0-1$ ) denote the probability that the OTU is associated with the clutches samples, and indicate the probability of finding the OTU in clutches samples, respectively

\begin{tabular}{|c|c|c|c|c|}
\hline & Frequency & Rel. abund & Specificity & Sensitivity \\
\hline \multicolumn{5}{|l|}{ rbcL OTUs } \\
\hline Chlamydomonadaceae; Chlamydomonas gloeophila (99.4\%)* & 19 & $14.2 \%$ & 0.994 & 0.679 \\
\hline Chlamydomonadaceae; Chlamydomonas globosa $(92.2 \%)^{*}$ & 19 & $4.8 \%$ & 0.971 & 0.679 \\
\hline Bacillariophyceae; Nitzschia palea $(100 \%)^{*}$ & 19 & $2.4 \%$ & 0.965 & 0.679 \\
\hline Chlamydomonadaceae; Oophila sp. $(99.7 \%)^{*}$ & 18 & $14.4 \%$ & 1 & 0.643 \\
\hline Pleurastraceae; Pleurastrum sp. $(94.3 \%)^{*}$ & 18 & $1.1 \%$ & 0.844 & 0.643 \\
\hline Chlamydomonadaceae; Chlamydomonas sp. $(93.8 \%)^{* *}$ & 17 & $2.6 \%$ & 0.531 & 0.607 \\
\hline Chlamydomonadaceae; Chlamydomonas sp. (97.3\%)* & 14 & $6.5 \%$ & 1 & 0.500 \\
\hline Chlorellaceae; Nannochloris sp. (89.9\%) & 14 & $2.2 \%$ & 0.350 & 0.500 \\
\hline Trebouxiophyceae; Choricystis sp. (97.3\%) & 13 & $17.1 \%$ & 0.283 & 0.464 \\
\hline Ulotrichaceae; Gloeotilopsis planctonica (86\%) & 10 & $3.1 \%$ & 0.278 & 0.357 \\
\hline \multicolumn{5}{|l|}{ 18S OTUs } \\
\hline Unclassified Chlamydomonadales $(98.4 \%)^{*}$ & 15 & $8.5 \%$ & 1 & 0.536 \\
\hline Unclassified Bacillariophyceae $(99.2 \%)^{*}$ & 15 & $2.0 \%$ & 0.950 & 0.536 \\
\hline Alveolata; Hemiurosomoida longa $(99.2 \%)^{*}$ & 14 & $6.9 \%$ & 1 & 0.500 \\
\hline Ochrophyta; Mallomonas sp. (99.2\%)* & 13 & $4.2 \%$ & 0.888 & 0.464 \\
\hline Chlamydomonadaceae; Chloromonas oviformis (100\%)* & 13 & $2.3 \%$ & 0.827 & 0.464 \\
\hline Chlamydomonadaceae; Chloromonas subdivisa $(100 \%)^{*}$ & 13 & $2.1 \%$ & 0.881 & 0.464 \\
\hline Chlamydomonadaceae; Chlamydomonas acidophila $(100 \%)^{*}$ & 10 & $4.8 \%$ & 0.980 & 0.357 \\
\hline Chlamydomonadaceae; Oophila sp. (100\%)* & 6 & $8.9 \%$ & 1 & 0.214 \\
\hline Ochrophyta; Hibberdia magna $(92.1 \%)^{*}$ & 6 & $7.3 \%$ & 1 & 0.214 \\
\hline Unclassified Fungi $(93.9 \%)^{*}$ & 5 & $5.2 \%$ & 1 & 0.179 \\
\hline
\end{tabular}

Table 2 PERMANOVA (Type I SS, reads per sample as a covariate) results for rbcL and $18 \mathrm{~S}$ metabarcoding data sets (based on operational taxonomic units (OTU) tables, Online Resource 5) to test the effect of 'substrate', 'sampling site' and 'sampling date' on the algal (rbcL) and micro-eukaryotic (18S) communities. Tests were performed using the Bray-Curtis similarity matrix based on the Log-transformed sequence data, as well as on the UniFrac distance matrix based on the Maximum-likelihood phylogenetic trees of OTUs. Factor 'substrate' includes four categories: samples of leaves $(n=24)$, sediments $(n=24)$, water $(n=24)$ and clutches $(n=28)$. Factor 'sampling site' includes three categories: Lelm1 $(n=34)$, Lelm2 $(n=34)$, Dahlum $(n=32)$. Factor 'sampling date' includes nine categories: 25-Feb-19 $(n=9), 12-\mathrm{Mar}-$ $19(n=9), 25-M a r-19$ ( $n=15), 28-M a r-19(n=15), 05-A p r-19(n=15)$, 11-Apr-19 $(n=15), 18$-Apr-19 $(n=13), 13-J u n-19(n=9)$. Factor values after the covariate indicate test results when the respective factor was included in the model as the last one (Type I analyses)

\begin{tabular}{|c|c|c|c|c|c|c|c|}
\hline & \multirow[b]{2}{*}{ df } & \multicolumn{3}{|c|}{ Bray-Curtis matrix } & \multicolumn{3}{|c|}{ UniFrac matrix } \\
\hline & & $\mathrm{R}^{2}$ & pseudo-F & $P$-value & $\mathrm{R}^{2}$ & pseudo-F & $P$-value \\
\hline \multicolumn{8}{|l|}{ Factor (rbcL) } \\
\hline Covariate(reads) & 1 & 0.032 & 7.325 & $<0.001$ & 0.024 & 5.1404 & 0.006 \\
\hline Substrate & 3 & 0.205 & 15.924 & $<0.001$ & 0.176 & 12.472 & $<0.001$ \\
\hline Sampling site & 2 & 0.153 & 17.751 & $<0.001$ & 0.112 & 11.903 & $<0.001$ \\
\hline Sampling date & 7 & 0.076 & 2.511 & $<0.001$ & 0.066 & 2.0197 & 0.005 \\
\hline \multicolumn{8}{|l|}{ Factor $(18 \mathrm{~S})$} \\
\hline Covariate(reads) & 1 & 0.037 & 10.209 & $<0.001$ & 0.047 & 11.499 & $<0.001$ \\
\hline Substrate & 3 & 0.146 & 13.383 & $<0.001$ & 0.135 & 11.028 & $<0.001$ \\
\hline Sampling site & 2 & 0.072 & 9.867 & $<0.001$ & 0.050 & 6.0527 & $<0.001$ \\
\hline Sampling date & 7 & 0.075 & 2.944 & $<0.001$ & 0.074 & 2.5864 & $<0.001$ \\
\hline
\end{tabular}



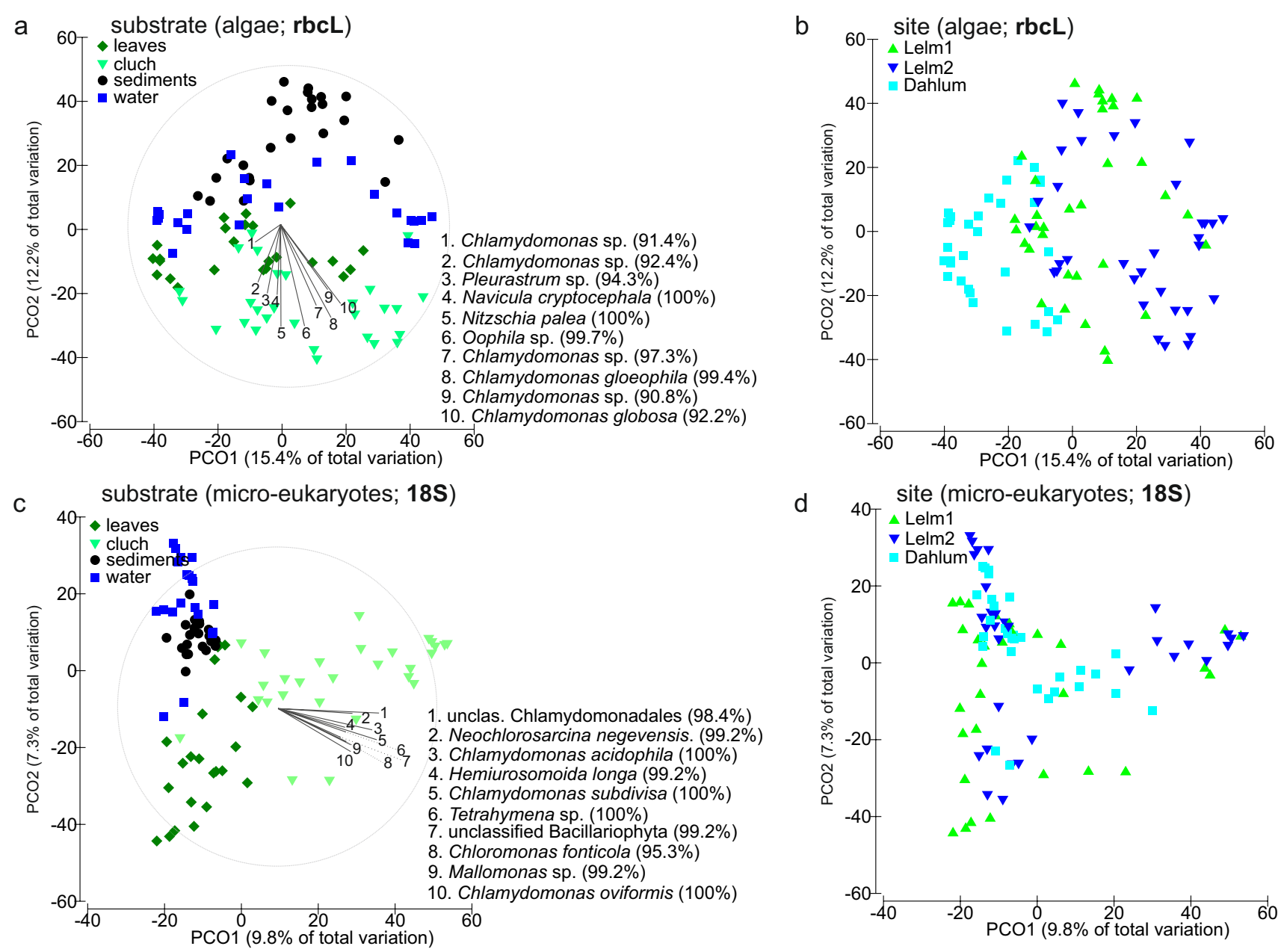

Fig. 4 Principal coordinates analysis (PCO) ordination plots (based on Bray-Curtis matrices) for algal (rbcL; a-b) and micro-eukaryotic $(18 \mathrm{~S}$; c-d) communities from all sampled substrates and sites. Vectors in a and c plots denote (Spearman) correlation vectors of 10 most

other Stramenopiles (30\%, 9 OTUs), Fungi (10\%, 3 OTUs), Chiliophora (10\%, 3 OTUs) and Euglenozoa (3\%, 1 OTU) in the $18 \mathrm{~S}$ data set (Online Resource 4, Fig. S4).

Since PERMANOVA showed significant differences in OTU composition between sampling sites (Table 2, Fig. 4), indicator species analyses were also performed separately for the $R$. dalmatina clutch samples from each site (Lelm1, Lelm2, Dahlum). The analyses revealed 21, 12, and 6 algal (rbcL) OTUs from the three sampling sites, respectively, that were identified as characteristic to clutch samples (Online Resource 3). For the same sites, indicator species analyses for micro-eukaryotes (18S data) found 6, 18, and 25 indicator OTUs from clutch samples (Online Resource 3). The PERMANOVA analyses, only with indicator OTUs for clutch samples, also demonstrated the significant effect of sampling site $\left(\mathrm{R}^{2}=0.357, P<0.001\right.$ and $\mathrm{R}^{2}=0.299$, $P<0.001$ for algae and micro-eukaryotes, respectively; important indicator operational taxonomic units (OTUs) in Rana dalmatina clutch samples. The percentage in the parentheses after indicator OTU represent the blastn identity percentage for that taxon (i.e. first blastn match)

Online Resource 4, Fig. S5). In general, the ponds that were close together (i.e., the two proximate sampling sites of Lelm1 and Lelm2) shared a higher number of indicator OTUs from clutch samples (Online Resource 4, Fig. S6), thus had more similar communities (Online Resource 4, Fig. S5).

Taxa associated with R. dalmatina clutches also displayed temporal distance decay of similarity patterns (Fig. 6). This was statistically significant for the algal (rbcL) communities in the sampling site Lelm1, whereas temporal distance did not affect the similarity between clutch samples from other sites (Lelm2 and Dahlum; Fig. 6c). Micro-eukaryotic (18S) communities associated with clutch samples were subjected to temporal distance decay of similarity at all sampling sites (Fig. 6d). The temporal distance decay of similarity patterns for algal and micro-eukaryotic communities in the clutch samples displayed the same patterns when including only 
a algae (rbcL)

Bray-Curtis

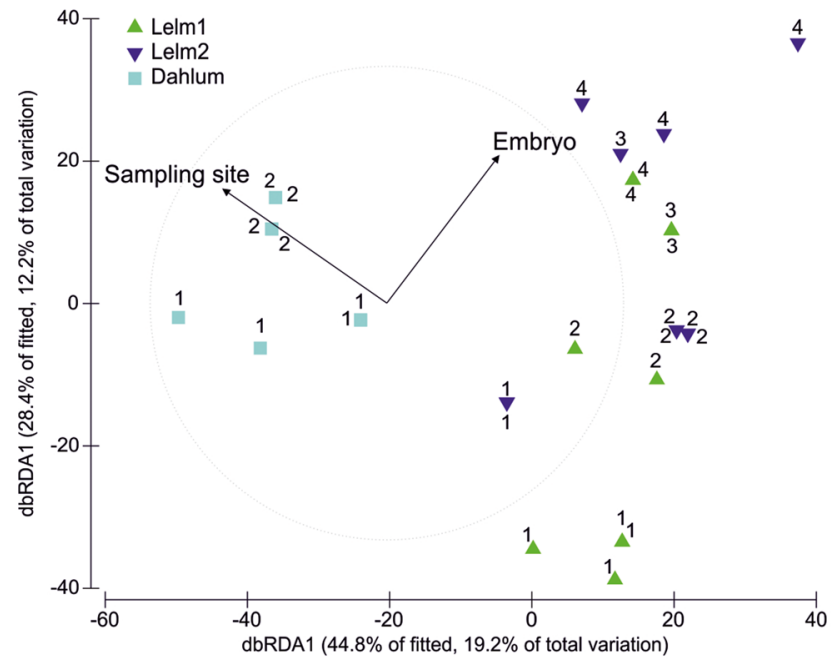

c micro-eukaryotes (18S)

Bray-Curtis

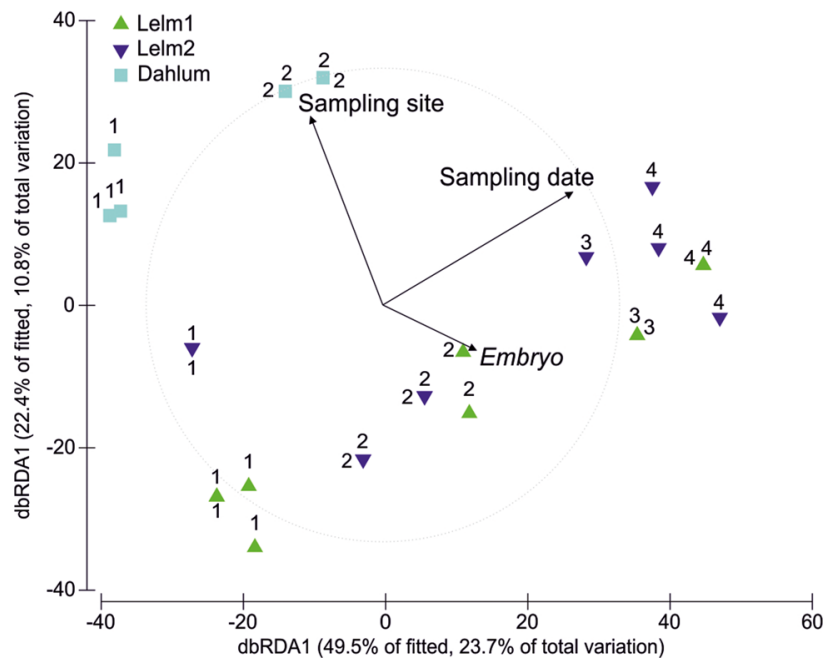

Fig. 5 Distance-based redundancy analysis (dbRDA) ordination plots for algal (rbcL; a-b) and micro-eukaryotic $(18 \mathrm{~S} ; \mathbf{c}-\mathbf{d})$ communities in Rana dalmatina clutch samples as based on Bray-Curtis similarity $(a, c)$ and UniFrac (b, d) distance matrices. Vectors on the plots represent the most important variables for the community compositions of

indicator OTUs to the temporal distance decay analyses (Online Resource 4, Fig. S7). Temporal distance decay patterns were also demonstrated by the communities associated with water and leaf samples but not with sediment samples (Online Resource 4, Fig. S8).

An exploratory analysis of all sequences of the $18 \mathrm{~S}$ rRNA gene from previous studies targeting Oophila (Correia et al. 2020; Kim et al. 2014; Muto et al. 2017; Nema et al. 2019) confirmed that strains assigned to Oophila in these studies belong to two distinct clades within Chlorophyta (Dataset b algae (rbcL)

UniFrac
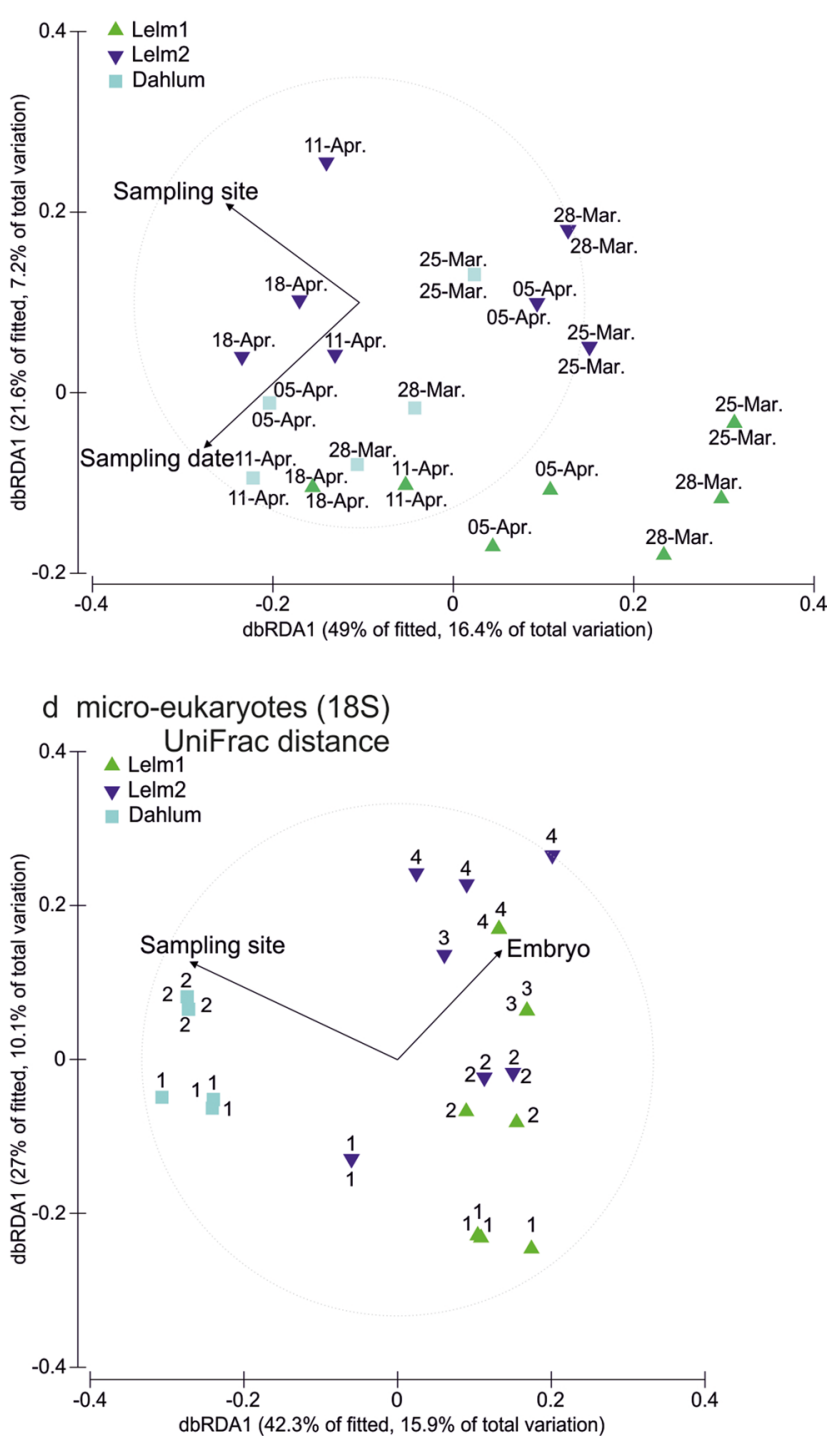

algae (rbcL) and micro-eukaryotic (18S) associated with the clutches as based on DistLM analyses. Numbers above individual dots denote the estimated embryo developmental stage categories. Dates above individual dots denote sampling dates. Two values associated with one dot indicate the two overlapping dots with the same coordinates

1; Online Resource 4, Fig. S9). A closer look specifically at these two clades (Dataset 3; Fig. 7) reconstructs those sequences associated to amphibian clutches considered as "Clade B" by Nema et al. (2019) as a monophyletic group. This group contains only a few isolates of free-living algae besides the clutch-associated ones, whereas the sequences of "Clade A" sensu Nema et al. (2019) are placed at different positions within a clade containing numerous free-living species of Chlorococcum. Most of the clutch-associated isolates in this clade have $18 \mathrm{~S}$ sequences identical or extremely 


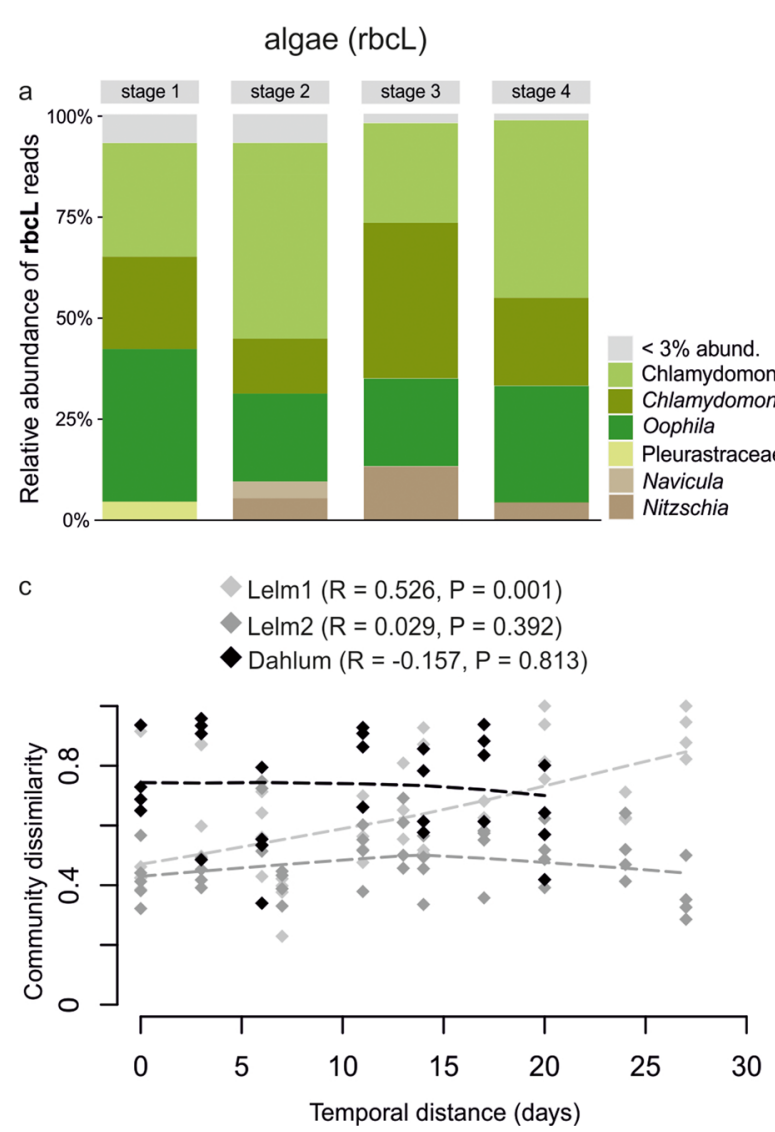

Fig. 6 Relative abundance of reads for indicator OTUs in the pooled Rana dalmatina clutch samples across embryo developmental stage categories $(\mathbf{a}-\mathbf{b})$, and relationships between $R$. dalmatina clutch-associated operational taxonomic units (OTUs) community dissimilarity and temporal distance for each sampling site (c-d).

similar to free-living strains of different Chlorococcum species, and the tree identifies seven independent, not directly related Chlorococcum-like lineages isolated from amphibian clutches. Samples associated to $R$. dalmatina clutches in Germany are found in both main clades: the $18 \mathrm{~S}$ sequences identified as Oophila in our metabarcoding study cluster within "Clade B", whereas one isolate cultured from a clutch in 2018 is placed in "Clade A" (Fig. 7). The latter is nearly identical $(99.9 \%)$ in $18 \mathrm{~S}$ sequence to Canadian isolates from Sudden Tract (spelled Suddent Tract in the respective Genbank records; KY091670) and Kingston, Ontario (KY091671). Phylogenetic analysis based on a comprehensive multigene data set (Fig. 8) confirms with maximum support that representatives of the two main clades are not closely related to each other and belong to phylogenetically distant groups of green algae.

An analysis of the metabarcoding OTU representative $18 \mathrm{~S}$ sequences along with selected sequences of green algae (Dataset 2; Online Resource 4, Fig. S10) revealed that in our study ponds in the Elm region, clutches of $R$. dalmatina were micro-eukaryotes (18S)

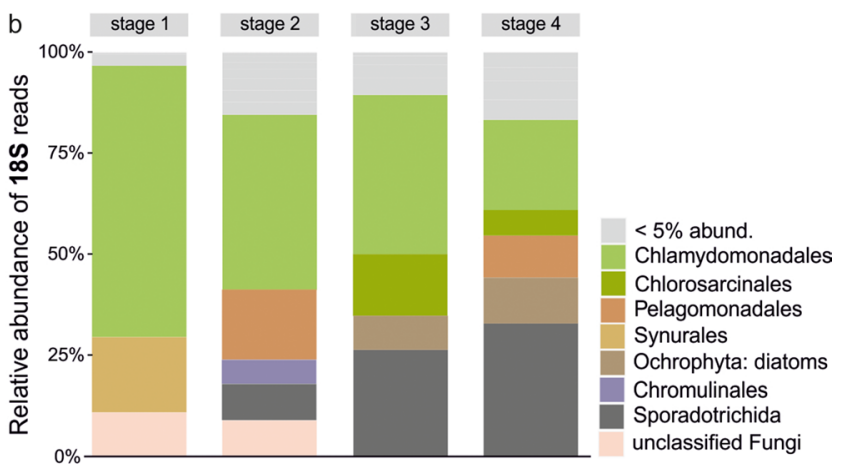

$\begin{array}{ll}\mathrm{d} & \operatorname{Lelm1}(\mathrm{R}=0.641, \mathrm{P}<0.001) \\ & \operatorname{Lelm} 2(\mathrm{R}=0.725, \mathrm{P}<0.001) \\ & \text { Dahlum }(\mathrm{R}=0.396, \mathrm{P}=0.016)\end{array}$

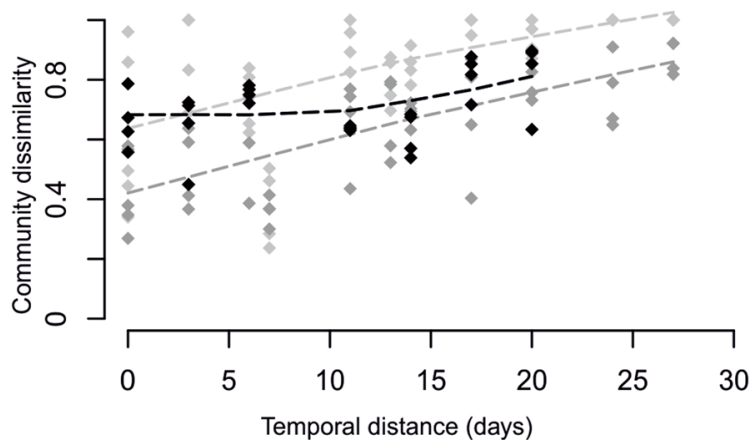

OTUs annotated to order level for $18 \mathrm{~S}$ data (a) and to genus level for rbcL indicator OTUs (b). Higher level taxa in b plot indicate that blastn match was lower than $95 \%$, thus the OTU was not annotated to genus level

colonized by a plethora of green algae of distinct phylogenetic positions. Forty-eight OTUs (18S data) of green algae identified from clutches were included in the tree; besides Chlorococcum and Oophila, some of these matched reference sequences of algae as diverse as Chlamydomonas, Chloromonas, Chlorosarcina, Planophila, and Tetracystis. Moreover, the rbcL data contained 214 clutch-associated green algal OTUs. Besides Chlamydomonas and Oophila (Fig. 2a, b), other frequently occurring green algae were assigned to genera such as Microthamnion, Nannochloris, and Choricystis. Since the rbcL primers used herein target only a few algal groups, but $18 \mathrm{~S}$ primers are universal across a wide range of micro-eukaryotes, the detected clutch-associated green algal communities varied between these two markers. Clutch-associated green algal genera detected with rbcL and 18S are outlined in Online Resource 4, Fig. S12. The rbcL phylogenetic analysis (Dataset 6; Online Resource 4, Fig. S14) did not resolve any of the deeper nodes in the green algae tree with bootstrap support but further confirmed 
that "Clade A" is a paraphyletic assemblage of isolates related to different free-living green algae.

\section{Discussion}

\section{Amphibian clutches as ecosystem for algae and other micro-eukaryotes}

In our study, DNA metabarcoding revealed that $R$. dalmatina clutches in the Elm region (Germany) provide a distinct ecosystem for an array of algae and other micro-eukaryotes. More than 300 algal OTUs (rbcL marker) and nearly 200 micro-eukaryotic OTUs (18S marker) were detected in the clutch samples. In contrast to the recent metabarcoding study of the North American salamander Ambystoma maculatum egg capsules, where Jurga et al. (2020) found no evidence for algal lineages outside the 'Oophila' clade (according to Kim et al. 2014) colonizing the salamander's eggs, our data contained a wide range of algae associated to $R$. dalmatina clutches. Because the egg capsules of $R$. dalmatina are less compact compared to those of A. maculatum, especially in later stages of development, it is difficult to isolate exactly the inner capsule. Therefore, the clutch samples in our study may be prone to an inevitable 'environmental contamination' with algae that are not strictly inside the egg capsule. Some of the detected taxa may therefore occur on the surface of the clutch or in cavities between egg capsules rather than within the capsular chambers directly surrounding the eggs.

Besides green algae, we often detected diatoms in clutch samples of $R$. dalmatina. Marine diatoms are known to live in the gelatinous egg masses of polychaetes (Chaffee and Strathmann 1984; Strathmann 2000) and mollusks (Biermann et al. 1992; Cohen and Strathmann 1996). This symbiotic relationship is likely beneficial for both partners (Peyton et al. 2004), but so far, no studies on the colonization of diatoms of clutches of Rana or other amphibians have been published. The benthic diatoms Nitzschia palea, Navicula cryptocephala, and $N$. tripunctata detected in our study are widespread and common species (Lange-Bertalot et al. 2017). It is very likely that they use $R$. dalmatina clutches as a substrate (micro-habitat), i.e., they live on them and not inside, which may speak against a close symbiotic relationship.

Nevertheless, the identified algal and other microeukaryotic communities associated with frog clutches had very distinctive compositions compared with the communities in other environmental samples in our study (Fig. 4), with more than 20 indicator OTUs in this micro-habitat (Online Resource 3). Although we sampled seemingly similar ponds, we found a relatively strong effect of the location on algal and micro-eukaryotic community structures, similar to observations by Jurga et al. (2020). Moreover, in an exploratory metabarcoding study of clutches of the related host Rana parvipalmata from a pond in northwestern Spain, with very clear water on granitic soil, the rbcL and $18 \mathrm{~S}$ data of samples processed in exactly the same way revealed no traces of any other green algae except Oophila, and very few additional micro-eukaryotes (data to be in-depth analyzed in future studies; list of OTUs in Online Resource 1, Table S6). This suggests that the composition of the community colonizing amphibian clutches can drastically differ depending on environmental properties. The ponds in the Elm are rather nutrient-rich, on substrate characterized by limestone components and with often turbid water and muddy bottom. This is possibly favoring the growth of numerous green algae and other micro-eukaryotes, whereas nutrient-poor environments (like that of the $R$. parvipalmata clutches sampled with identical methodology; Online Resource 1, Table S6) may harbor a less diverse reservoir of potential clutch colonizers. Moreover, we observed a temporal distance decay of similarity of the clutch-associated communities, which most probably was linked to changes in the environment over time (Online Resource 4, Fig. S8). This further confirms that local conditions are affecting the clutch-associated communities of algae and other micro-eukaryotes. As stated before, probably not all clutch-associated taxa identified in our study colonize the inner egg capsule. Yet, it appears that, depending on the habitat characteristics, amphibian clutches may attract numerous species of algae and other micro-eukaryotes outside of the 'Oophila' clade(s) to exploit this micro-habitat.

\section{rbcL vs. 185 gene markers for metabarcoding}

Overall, we found comparable community structuring patterns between rbcL vs. 18S metabarcoding data (Fig. 5, Table 2). However, as expected, the taxonomic resolution varied between markers (Figs. 2 and 3, Table 1). The universal $18 \mathrm{~S}$ primers target a broad range of micro-eukaryotic linages, whereas rbcL primers capture a subset of photosynthetic micro-algae, which presumably only represent a subset of the micro-eukaryotes detected with the $18 \mathrm{~S}$ marker. Furthermore, by applying the same clustering threshold (97\%), the number of OTUs was higher in the rbcL metabarcoding data set. In the clutch samples, more than 200 rbcL OTUs were identified as green algae, but less than 50 green algal OTUs were identified via $18 \mathrm{~S}$ amplicons. It is acknowledged that the choice of primers affects the results of biodiversity assessments (Hajibabaei et al. 2019; Horton et al. 2017; Piñol et al. 2019; Tedersoo et al. 2015). The relatively 

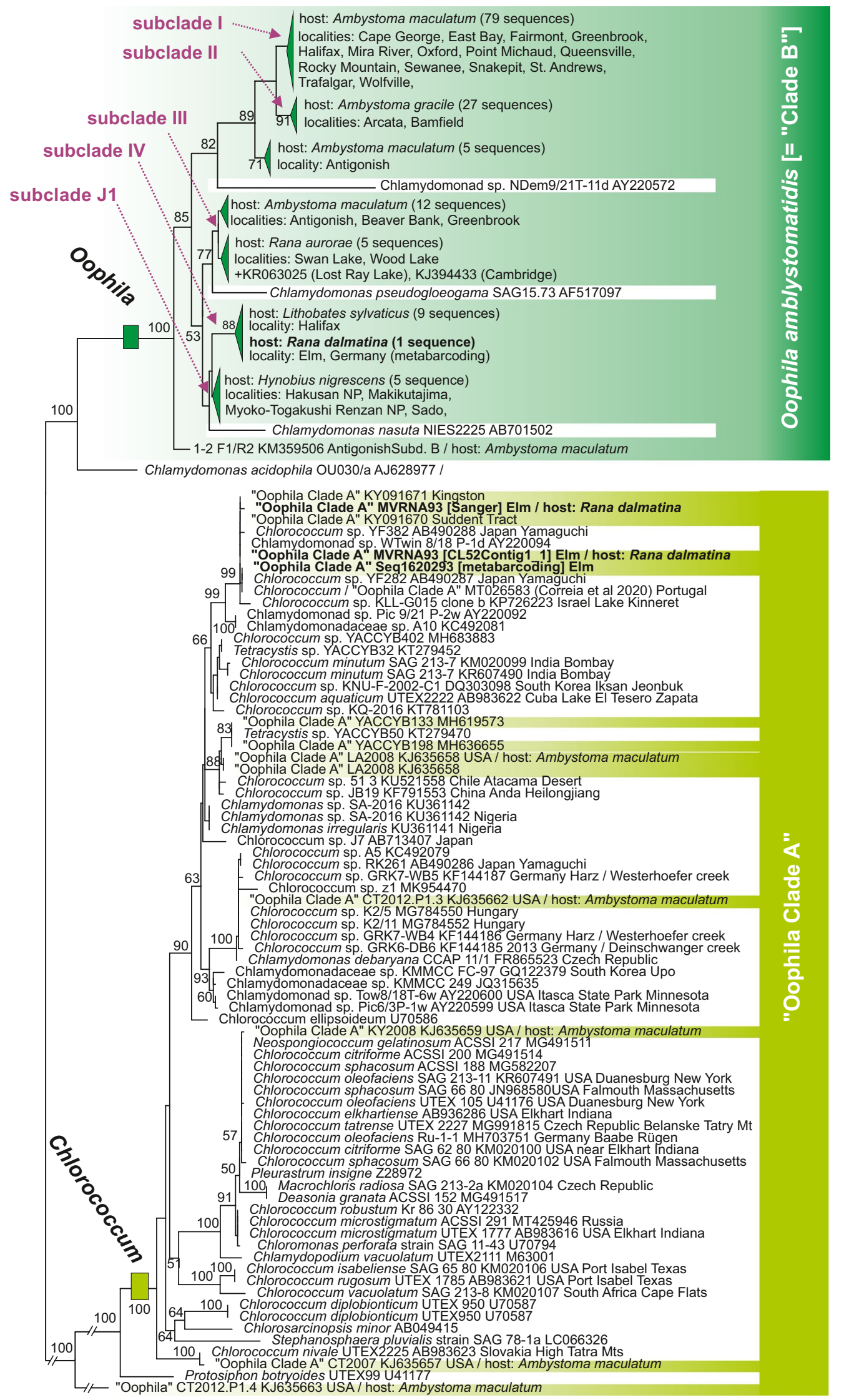
4Fig. 7 Maximum Likelihood tree inferred from DNA sequences of the $18 \mathrm{~S}$ rRNA gene (Dataset 3; $1878 \mathrm{bp}$ ) comprising all sequences assigned to the Oophila clade and the Chlorococcum clade in the exploratory analysis of Dataset 1 (Online Resource 4, Fig. S9). Terminals with identical or very similar sequences have been merged; see Online Resource 4, Fig. S11 for an expanded tree with all terminals and their Genbank accession numbers. Dark green marks the clade of amphibian-associated Oophila ("Clade B" according to Nema et al. 2019) with subclades according to Kim et al. (2014) and Muto et al. (2017), light green marks the Oophila-like lineages found associated to amphibians within the Chlorococcum clade ("Clade A" according to Nema et al. 2019). Numbers at nodes show bootstrap values in percent (only shown if $>50 \%$, and removed from the shallowest nodes for better graphical representation) conserved $18 \mathrm{~S}$ gene allows designing rather universal primers across multiple taxonomic groups; however, with the universality, there is an expected loss in resolution. The low variability within the $18 \mathrm{~S}$ gene has been demonstrated for multiple taxonomic groups (Anslan and Tedersoo 2015; Tang et al. 2012), including green algae (Hall et al. 2010). Therefore, the lower richness of green algae associated with the frog clutches in the $18 \mathrm{~S}$ data set could partly result from the low resolution of that marker gene compared to rbcL, which possesses higher variability among green algae (Hall et al. 2010). Nevertheless, the $18 \mathrm{~S}$ data set contained some green algal genera (alongside other micro-eukaryotes) that were not identified via rbcL amplicons (Online Resource
Fig. 8 Maximum Likelihood tree inferred from DNA sequences of 18 nuclear proteincoding genes after exclusion of hypervariable regions (Dataset 5; alignment length 4892 amino acids), comprising all Chlamydomonadales and related taxa for which sequences were available from the study of (Leebens-Mack et al. 2019), plus sequences extracted from transcriptomes of one Oophila strain isolated from a clutch of Ambystoma maculatum (dark green; corresponding to "Clade B" of Nema et al. (2019)) and of one Oophila-like representative of the Chlorococcum clade isolated from a clutch of Rana dalmatina (light green; corresponding to "Clade A" of Nema et al. (2019)). Numbers at nodes show bootstrap values in percent. See Online Resource 4, Fig. S13 for an extended tree containing all available taxa within Chlorophyta

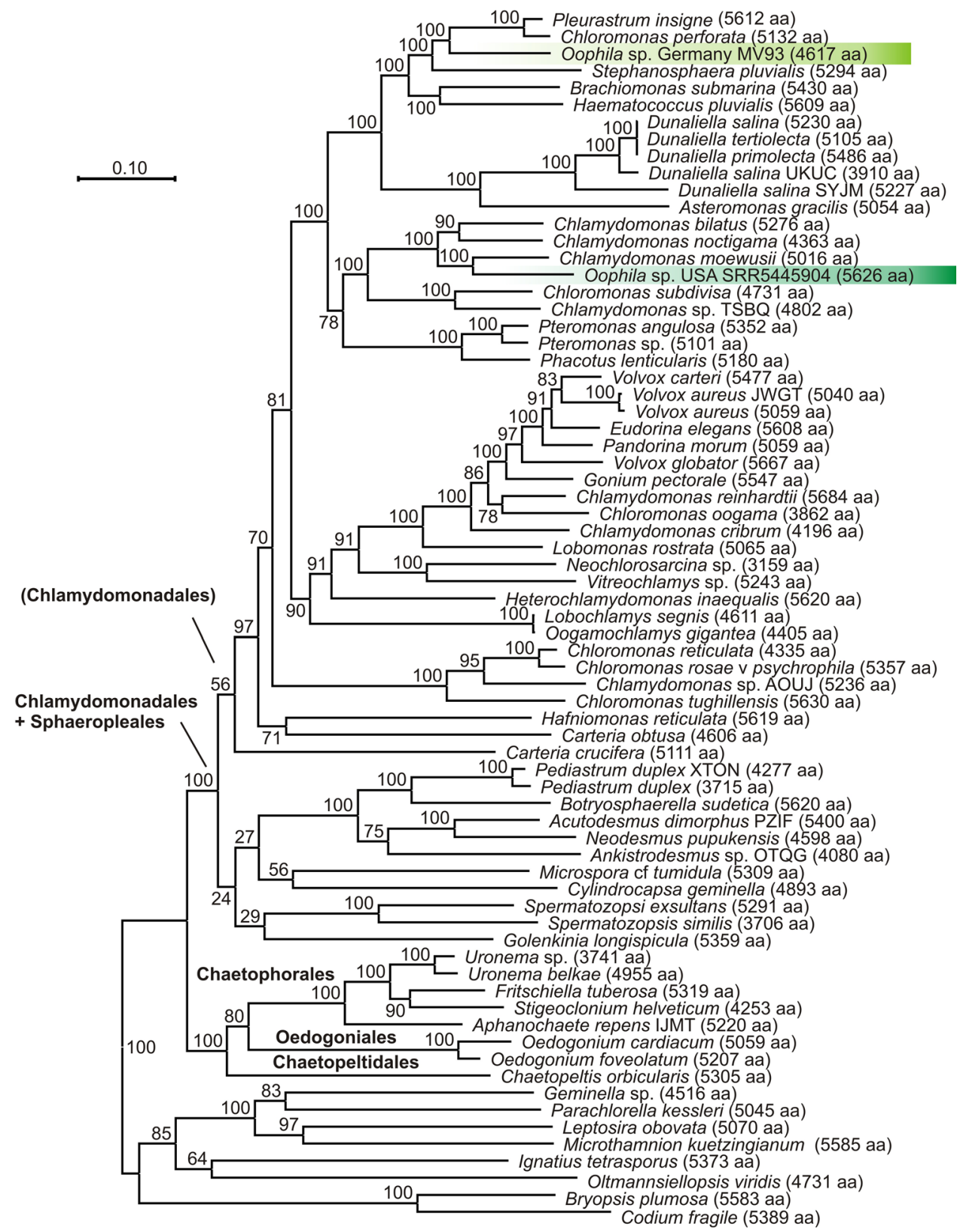


4, Fig. S12). Wider variety of detected taxa demonstrates the usefulness of multi-marker approaches, which has also been recognized in several other metabarcoding studies (Adamowicz et al. 2019; da Silva et al. 2019; Zhang et al. 2018).

\section{Occurrence and relationships of amphibian clutch-associated green algae in Europe}

Isolates of Oophila amblystomatis associated to amphibian clutches have so far been identified by molecular means from North America and Japan (Kim et al. 2014; Muto et al. 2017; Nema et al. 2019). Our study provides the first molecular confirmation of the occurrence of Oophila from Central Europe where the occurrence of green algae in clutches of Rana dalmatina and $R$. temporaria has previously been reported based on microscopic examination (Baumgartner et al. 1996; Fernández de Larrea González 2018). Interestingly, Baumgartner et al. (1996) observed that R. dalmatina clutches were more intensively colonized by green algae than $R$. temporaria clutches, even under sympatric occurrence of the two host species.

One of the most common green alga (Table 1) in our $18 \mathrm{~S}$ metabarcoding data set from $R$. dalmatina clutches matched sequences commonly assigned to Oophila (e.g., Jurga et al. 2020; Kerney 2011; Kerney et al. 2011; Kim et al. 2014; Muto et al. 2017) and considered as "Clade B" by Nema et al. (2019) (Fig. 7). Algae belonging to Oophila "Clade B" have rarely been found free-living: as one of the few examples, Lin and Bishop (2015) detected them via environmental DNA sequencing from amphibian breeding ponds in North America, and the respective 18S clade in Fig. 7 contains sequences from a few further isolates available in Genbank and flagged as free-living (named as unidentified chlamydomonad, Chlamydomonas nasuta, and C. pseudogloegama, respectively). In our study, OTUs assigned to Oophila "Clade B" (with $>97 \%$ sequence similarity) were not detected from other environments, confirming that this clade mostly contains strict symbionts associated to amphibian clutches that are infrequent outside of this habitat.

Within this clade, previous studies (Kim et al. 2014; Muto et al. 2017) defined several subclades with a certain degree of host-specificity: subclade I was isolated from the salamander Ambystoma maculatum, subclade II from A. gracile, subclade III from the frog Rana aurora and from $A$. maculatum, subclade IV from the frog Lithobates sylvatica, and subclade $\mathrm{J} 1$ from the salamander Hynobius nigrescens. The "Clade B" $18 \mathrm{~S}$ sequence from our metabarcoding data set clustered with subclade IV without sequence differences to North American sequences (Fig. 7). Although based on very short DNA sequences only, this provides preliminary evidence for a widespread occurrence of Oophila strains across the Holarctic.
Our metabarcoding data revealed numerous other algae in $R$. dalmatina clutches, many of which we consider as opportunistic colonizers of these egg masses. Several of these, however, have sequences matching those of algae considered to belong to Oophila "Clade A" according to Nema et al. (2019) (Online Resource 4, Fig. S10). Full 18S sequences from a culture isolated from an $R$. dalmatina clutch (isolate MVRNA93), both assembled from a transcriptome and obtained via Sanger sequencing, fully matched sequences KY091670-KY091671 from two Canadian "Clade A" samples (Fig. 7). This suggests that also green algae strains belonging to "Clade A" are widely distributed across both the Nearctic and Palearctic and readily colonize amphibian egg clutches.

However, given the relative scarcity of "Clade A" algae in metabarcoding studies from clutches, including our results herein, we assume that most of the reported benefits from the mutualistic algae-amphibian relationship refer to "Clade B" algae (e.g., Gilbert 1942; Gilbert 1944; Pinder and Friet 1994; Small and Bishop 2020 - all of whom examined A. maculatum). Whether a mutualistic relationship is maintained by "Clade A" algae remains to be seen. Anderson et al. (1971) and Bachmann et al. (1986) both found A. tigrinum embryonic mortality was positively correlated with egg capsule algae (but see Hutchison 1971 for a rebuttal). It is possible that these differences in symbiotic relationship are not due to the host salamander (A. tigrinum vs. the more commonly studied A. maculatum), but to the relative portion of "Clade A" vs. "Clade B" algae. Controlled co-culture studies with the different clades would help resolve these potentially dynamic interspecific relationships.

\section{Identity of Oophila amblystomatis}

Combining our DNA metabarcoding and phylogenetic results allows us to draw conclusions on the identity of $O$. amblystomatis and, thereby, the monotypic genus Oophila itself. Most recent studies have considered isolates phylogenetically belonging to "Clade B" to represent this genus (e.g. Kerney 2011; Kerney et al. 2011; Kim et al. 2014; Muto et al. 2017). However, Nema et al. (2019) suggested that "Clade A" may represent this genus, based on analysis of numerous isolates, some of which were obtained from amphibian clutches collected close to the presumptive type locality of $O$. amblystomatis, Middlesex Fells in Massachusetts. O. amblystomatis (Lambert ex Wille 1909) species was originally named informally by F.D. Lambert in 1905 based on samples of algal cells collected and preserved from Ambystoma maculatum embryos (at the time called Amblystoma punctatum), but no genetic information or living type strain exists from the original materials. While a final resolution of the conundrum can only be achieved after careful examination of all historical evidence, including Lambert's original 
materials (curated by Craig Schneider at Trinity College, Connecticut, according to information in Nema et al. 2019, who erroneously wrote about type species rather than type specimen when referring to this material), the results of the present study suggest that algae more strictly and more frequently associated to amphibian clutches belong to "Clade B". Therefore, we hypothesize that Lambert's observations also referred to representatives of this clade.

As a first line of evidence, our initial efforts to isolate algae from $R$. dalmatina clutches in the Elm yielded one isolate (MVRNA93) belonging to "Clade A" and identical in its $18 \mathrm{~S}$ sequence to two Canadian samples (KY091670, KY091671) from the work of Nema et al. (2019). No isolate belonging to "Clade B" was obtained. However, according to the DNA metabarcoding data, the "Clade A" alga is exceedingly rare in the $R$. dalmatina clutches, whereas "Clade B" algae (here considered as Oophila) had the highest read numbers of any algal taxon in the clutch samples. Therefore, it is likely that "Clade B" algae are more difficult to culture than (many) "Clade A" algae, and the latter are, therefore, more successfully isolated and cultured (or have a high likelihood to contaminate other isolates, even if present in only very minor proportion in a sample). Two other recent studies are in agreement with this hypothesis: firstly, the DNA metabarcoding study of Jurga et al. (2020) only found "Clade B" sequences in numerous North American salamander clutches studied; and secondly, Correia et al. (2020) obtained a free-living "Clade A" isolate from a pond in Portugal, which they specifically characterize as robust and with promising growth performance even at industrial scale.

Secondly, our phylogenetic analysis (Fig. 7), including all $18 \mathrm{~S}$ sequences assigned to Oophila in previous studies plus sequences of other algae with BLAST matches, suggests that "Clade A" is a conglomerate of not directly related algae, numerous samples of which are identical or near-identical with isolates of free-living algae of the genus Chlorococcum. This is particularly obvious for two isolates from Ambystoma maculatum clutches: sequence KJ635657 is identical to a sequence of $C$. nivale (AB983623), and KJ635659 agrees with sequences of numerous nominal Chlorococcum species such as $C$. citriforme, $S$. sphacosum, $C$. oleofaciens, $C$. elkhartiense, and $C$. tatraense. For other amphibian clutchassociated sequences of "Clade A", matching sequences are from unnamed free-living Chlorococcum originating from a diverse array of countries and continents (Chile, China, Czech Republic, Germany, Hungary, Israel, Japan, Portugal, Slovakia), suggesting these are ecological generalists occurring globally.

Upon finding sequences of Oophila "Clade A" clustering with Chlorococcum, Correia et al. (2020) suggested transferring $O$. amblystomatis to the genus Chlorococcum, and treated the species as Chlorococcum amblystomatis.
While we agree that "Clade A" algae should be assigned to Chlorococcum, we disagree with the conclusion regarding the species name amblystomatis. Instead, we suggest that it is biologically more probable and taxonomically more parsimonious to assign the nomen $O$. amblystomatis to the algae in "Clade B", which based on DNA metabarcoding have been found to be numerically most abundant in amphibian clutches in North America (Jurga et al. 2020), Europe (this study) and potentially Japan (Muto et al., 2017). "Clade B" appears to be more strictly associated to amphibian clutches than those algae of "Clade A", which may only opportunistically and occasionally colonize this micro-environment. According to our phylotranscriptomic analysis, "Clade B" appears to belong to a clade mostly consisting of Chlamydomonas rather than Chlorococcum species, and a final conclusion on the genus name Oophila will therefore only be possible after a more comprehensive taxonomic revision of the Chlamydomonadales.

Supplementary Information The online version contains supplementary material available at https://doi.org/10.1007/s00114-021-01734-0.

Acknowledgements We are grateful to Meike Kondermann and Josmaily Loriga Piñeiro for their help in the exploratory analyses, and Pedro Galán for his help in the field in northern Spain.

Funding Open Access funding enabled and organized by Projekt DEAL. Funding for S.A. was provided through the Deutsche Forschungsgemeinschaft (DFG; grant 317513741) via the International Research Training Group GRK 2309 "Geoecosystems in transition on the Tibetan Plateau (TransTiP)". Funding for R.K. was provided through the Gordon and Betty Moore Foundation (Grant \#GBMF5604; https:// doi.org/10.37807/GBMF5604).

Data and materials availability Raw Illumina MiSeq metabarcoding data is deposited in the Sequence Read Archive (SRA), BioProject ID: PRJNA714784. Raw Illumina NextSeq metatranscriptomics data is deposited in SRA, BioProject ID: PRJNA712983. The 18S sequence of an algal isolate MVRNA93 from Rana dalmatina clutch has been deposited in Genbank, under accession number MW723501.

Code availability Herein used R codes are available in Online Resource 6.

\section{Declarations}

Conflict of interest The authors declare no competing interests.

Open Access This article is licensed under a Creative Commons Attribution 4.0 International License, which permits use, sharing, adaptation, distribution and reproduction in any medium or format, as long as you give appropriate credit to the original author(s) and the source, provide a link to the Creative Commons licence, and indicate if changes were made. The images or other third party material in this article are included in the article's Creative Commons licence, unless indicated otherwise in a credit line to the material. If material is not included in the article's Creative Commons licence and your intended use is not permitted by statutory regulation or exceeds the permitted use, you will need to obtain permission directly from the copyright holder. To view a copy of this licence, visit http://creativecommons.org/licenses/by/4.0/. 


\section{References}

Adamowicz SJ, Boatwright JS, Chain F, Fisher BL, Hogg ID, Leese F, Lijtmaer DA, Mwale M, Naaum AM, Pochon X (2019) Trends in DNA barcoding and metabarcoding. Genome 62:5-8

Altig R, McDiarmid RW (2007) Morphological diversity and evolution of egg and clutch structure in amphibians. Herpetol Monogr 21:1-32

Amaral-Zettler LA, McCliment EA, Ducklow HW, Huse SM (2009) A method for studying protistan diversity using massively parallel sequencing of V9 hypervariable regions of small-subunit ribosomal RNA genes. PLoS ONE 4:e6372

Anderson JD, Hassinger DD, Dalrymple GH (1971) Natural mortality of eggs and larvae of Ambystoma t. tigrinum. Ecology 52:1107-1112

Anslan S, Tedersoo L (2015) Performance of cytochrome c oxidase subunit I (COI), ribosomal DNA Large Subunit (LSU) and Internal Transcribed Spacer 2 (ITS2) in DNA barcoding of Collembola. Eur J Soil Biol 69:1-7

Anslan S, Bahram M, Hiiesalu I, Tedersoo L (2017) PipeCraft: flexible open-source toolkit for bioinformatics analysis of custom high-throughput amplicon sequencing data. Mol Ecol Resour 17:e234-e240

Bachmann MD, Carlton RG, Burkholder JM, Wetzel RG (1986) Symbiosis between salamander eggs and green algae: microelectrode measurements inside eggs demonstrate effect of photosynthesis on oxygen concentration. Can J Zool 64:1586-1588

Baumgartner C, Bitschi N, Ellinger N, Gollmann B, Gollmann G, Köck M, Lebeth E, Waringer-Löschenkohl A (1996) Laichablage und Embryonalentwicklung von Springfrosch (Rana dalmatina Bonaparte, 1840) und Grasfrosch (Rana temporaria Linnaeus, 1758) in einem syntopen Vorkommen. Herpetozoa 9:133-150

Beattie RC (1980) A physico-chemical investigation of the jelly capsules surrounding eggs of the common frog (Rana temporaria temporaria). J Zool 190:1-25

Benson DA, Cavanaugh M, Clark K, Karsch-Mizrachi I, Lipman DJ, Ostell J, Sayers EW (2013) GenBank. Nucleic Acids Res 41:D36-D42

Bianchini K, Tattersall GJ, Sashaw J, Porteus CS, Wright PA (2012) Acid water interferes with salamander-green algae symbiosis during early embryonic development. Physiol Biochem Zool 85:470-480

Biermann CH, Schinner GO, Strathmann RR (1992) Influence of solar radiation, microalgal fouling, and current on deposition site and survival of embryos of a dorid nudibranch gastropod. Mar Ecol Prog Ser 205-215

Blaustein AR, Hokit DG, O'Hara RK, Holt RA (1994) Pathogenic fungus contributes to amphibian losses in the Pacific Northwest. Biol Conserv 67:251-254

Bletz MC, Loudon AH, Becker MH, Bell SC, Woodhams DC, Minbiole KP, Harris RN (2013) Mitigating amphibian chytridiomycosis with bioaugmentation: characteristics of effective probiotics and strategies for their selection and use. Ecol Lett 16:807-820

Bock C, Jensen M, Forster D, Marks S, Nuy J, Psenner R, Beisser D, Boenigk J (2020) Factors shaping community patterns of protists and bacteria on a European scale. Environ Microbiol 22:2243-2260

Bolger AM, Lohse M, Usadel B (2014) Trimmomatic: a flexible trimmer for Illumina sequence data. Bioinformatics 30:2114-2120

Burns JA, Zhang H, Hill E, Kim E, Kerney R (2017) Transcriptome analysis illuminates the nature of the intracellular interaction in a vertebrate-algal symbiosis. Elife 6:e22054

Burns JA, Kerney R, Duhamel S (2020) Heterotrophic carbon fixation in a salamander-alga symbiosis. Front Microbiol 11:1815

Camacho C, Coulouris G, Avagyan V, Ma N, Papadopoulos J, Bealer K, Madden TL (2009) BLAST+: architecture and applications. BMC Bioinformatics 10:421
Chaffee C, Strathmann RR (1984) Constraints on egg masses. I. Retarded development within thick egg masses. J Exp Mar Biol Ecol 84:73-83

Chauhan A, Singh R (2019) Probiotics in aquaculture: a promising emerging alternative approach. Symbiosis 77:99-113

Clarke K, Gorley R (2006) PRIMER V6: User manual/tutorial. Primer-E Ltd Plymouth, 192pp

Cohen CS, Strathmann RR (1996) Embryos at the edge of tolerance: effects of environment and structure of egg masses on supply of oxygen to embryos. Biol Bull 190:8-15

Correia N, Pereira H, Silva JT, Santos T, Soares M, Sousa CB, Schüler LM, Costa M, Varela J, Pereira L (2020) Isolation, identification and biotechnological applications of a novel, robust, free-living Chlorococcum (Oophila) amblystomatis strain isolated from a local pond. Appl Sci 10:3040

da Silva LP, Mata VA, Lopes PB, Pereira P, Jarman SN, Lopes RJ, Beja P (2019) Advancing the integration of multi-marker metabarcoding data in dietary analysis of trophic generalists. Mol Ecol Resour 19:1420-1432

De Caceres M, Jansen F, De Caceres MM (2016) Package 'indicspecies'

Edgar RC (2013) UPARSE: highly accurate OTU sequences from microbial amplicon reads. Nat Methods 10:996-998

Fernández de Larrea González I (2018) Dinámica y prevalencia de la colonización de los huevos de Rana dalmatina por microalgas clorofíceas en el medio natural. Unpublished diploma thesis. Leioa: Universidad del País Vasco

Fisher MC, Garner TW (2020) Chytrid fungi and global amphibian declines. Nat Rev Microbiol 18:332-343

Gilbert PW (1942) Observations on the eggs of Ambystoma maculatum with especial reference to the green algae found within the egg envelopes. Ecology 23:215-227

Gilbert PW (1944) The alga-egg relationship in Ambystoma maсиlatum A case of symbiosis. Ecology 25:366-369

Goff LJ, Stein JR (1978) Ammonia: basis for algal symbiosis in salamander egg masses. Life Sci 22:1463-1468

Gomez-Mestre I, Touchon JC, Warkentin KM (2006) Amphibian embryo and parental defenses and a larval predator reduce egg mortality from water mold. Ecology 87:2570-2581

Gosner KL (1960) A simplified table for staging anuran embryos and larvae with notes on identification. Herpetologica 16:183-190

Grabherr MG, Haas BJ, Yassour M, Levin JZ, Thompson DA, Amit I, Adiconis X, Fan L, Raychowdhury R, Zeng Q (2011) Trinity: reconstructing a full-length transcriptome without a genome from RNA-Seq data. Nat Biotechnol 29:644-652

Graham ER, Fay SA, Davey A, Sanders RW (2013) Intracapsular algae provide fixed carbon to developing embryos of the salamander Ambystoma maculatum. J Exp Biol 216:452-459

Haas BJ, Papanicolaou A, Yassour M, Grabherr M, Blood PD, Bowden J, Couger MB, Eccles D, Li B, Lieber M (2013) De novo transcript sequence reconstruction from RNA-seq using the Trinity platform for reference generation and analysis. Nat Protoc 8:1494-1512

Haddad CFB, Prado CPA (2005) Reproductive modes in frogs and their unexpected diversity in the Atlantic forest of Brazil. Bioscience 55:207-217

Hajibabaei M, Porter TM, Wright M, Rudar J (2019) COI metabarcoding primer choice affects richness and recovery of indicator taxa in freshwater systems. PLoS ONE 14:e0220953

Hall TA (1999) BioEdit: a user-friendly biological sequence alignment editor and analysis program for Windows 95/98/NT. In: Nucleic acids symposium series. vol 41. [London]: Information Retrieval Ltd., c1979-c2000, pp 95-98

Hall JD, Fucikova KF, Lo C, Lewins LA, Karol KG (2010) An assessment of proposed DNA barcodes in freshwater green algae. Cryptogam Algol 31:529-555 
Horton DJ, Kershner MW, Blackwood CB (2017) Suitability of PCR primers for characterizing invertebrate communities from soil and leaf litter targeting metazoan $18 \mathrm{~S}$ ribosomal or cytochrome oxidase I (COI) genes. Eur J Soil Biol 80:43-48

Hughey MC, Delia J, Belden LK (2017) Diversity and stability of egg-bacterial assemblages: the role of paternal care in the glassfrog Hyalinobatrachium colymbiphyllum. Biotropica 49:792-802

Hutchison V (1971) On the Ambystoma egg-alga relationship. Herp Rev 3:82

Johnson JE, Belmont SF, Wagner RS (2008) DNA barcoding as a means to identify organisms associated with amphibian eggs. Herpetol Conserv Biol 3:116-127

Jurga E, Graham L, Bishop C (2020) Oophila is monophyletic within a three-taxon eukaryotic microbiome in egg masses of the salamander Ambystoma maculatum. Symbiosis 81:187-199

Kanz C, Aldebert P, Althorpe N, Baker W, Baldwin A, Bates K, Browne P, van den Broek A, Castro M, Cochrane G (2005) The EMBL nucleotide sequence database. Nucleic Acids Res 33:D29-D33

Kelly M, Boonham N, Juggins S, Killie P, Mann D, Pass D, Sapp M, Sato S, Glover R (2018) A DNA based diatom metabarcoding approach for Water Framework Directive classification of rivers. Bristol: Environment Agency

Kerney R (2011) Symbioses between salamander embryos and green algae. Symbiosis 54:107-117

Kerney R, Kim E, Hangarter RP, Heiss AA, Bishop CD, Hall BK (2011) Intracellular invasion of green algae in a salamander host. Proc Natl Acad Sci 108:6497-6502

Kerney R, Leavitt J, Hill E, Zhang H, Kim E, Burns J (2019) Cocultures of Oophila amblystomatis between Ambystoma maculatum and Ambystoma gracile hosts show host-symbiont fidelity. Symbiosis 78:73-85

Kim E, Lin Y, Kerney R, Blumenberg L, Bishop C (2014) Phylogenetic analysis of algal symbionts associated with four North American amphibian egg masses. PLoS ONE 9:e108915

Kumar S, Stecher G, Tamura K (2016) MEGA7: Molecular Evolutionary Genetics Analysis Version 7.0 for Bigger Datasets. Mol Biol Evol 33:1870-1874

Lange-Bertalot H, Hofmann G, Werum M, Cantonati M, Kelly MG (2017) Freshwater benthic diatoms of Central Europe: over 800 common species used in ecological assessment. vol 942. Koeltz Botanical Books Schmitten-Oberreifenberg

Leebens-Mack JH et al (2019) One thousand plant transcriptomes and the phylogenomics of green plants. Nature 574:679-685

Lewis L, Landberg T (2014) Evolutionary diversity of the symbiotic salamander algae, Oophila (Chlorophyta). Unpublished Genbank Submission

Lin Y, Bishop CD (2015) Identification of free-living Oophila amblystomatis (Chlorophyceae) from yellow spotted salamander and wood frog breeding habitat. Phycologia 54:183-191

Marco A, Blaustein AR (2000) Symbiosis with green algae affects survival and growth of northwestern salamander embryos. J Herpetol 34:617-621

McFadden G, Melkonian M (1986) Use of Hepes buffer for microalgal culture media and fixation for electron microscopy. Phycologia 25:551-557

McMurdie PJ, Holmes S (2013) phyloseq: an R package for reproducible interactive analysis and graphics of microbiome census data. PLoS ONE 8:e61217

Medlin L, Elwood HJ, Stickel S, Sogin ML (1988) The characterization of enzymatically amplified eukaryotic 16S-like rRNA-coding regions. Gene 71:491-499

Montiel JA, Beman MJ, Frank AC, Sexton JP (2019) Visualizing diversity and distribution patterns for microbial communities in vernal pools. In book: Vernal pool landscapes: past present and future studies from the herbarium number 20. Chico: California State University

Muto K, Nishikawa K, Kamikawa R, Miyashita H (2017) Symbiotic green algae in eggs of Hynobius nigrescens, an amphibian endemic to Japan. Phycol Res 65:171-174

Nema M, Hanson ML, Müller KM (2019) Phylogeny of the eggloving green alga Oophila amblystomatis (Chlamydomonadales) and its response to the herbicides atrazine and 2,4-D. Symbiosis 77:23-39

Oksanen J, Blanchet FG, Kindt R, Legendre P, Minchin PR, O'hara R, Simpson GL, Solymos P, Stevens M, Wagner H (2015) R package 'vegan': community ecology package

Ondov BD, Bergman NH, Phillippy AM (2011) Interactive metagenomic visualization in a Web browser. BMC Bioinformatics 12:385

Orr H (1888) Memoirs: note on the development of amphibians, chiefly concerning the central nervous system; with additional observations on the hypophysis, mouth, and the appendages and skeleton of the head. J Cell Sci 2:295-324

Petrisko JE, Pearl CA, Pilliod DS, Sheridan PP, Williams CF, Peterson CR, Bury RB (2008) Saprolegniaceae identified on amphibian eggs throughout the Pacific Northwest, USA, by internal transcribed spacer sequences and phylogenetic analysis. Mycologia 100:171-180

Peyton KA, Hanisak MD, Lin J (2004) Marine algal symbionts benefit benthic invertebrate embryos deposited in gelatinous egg masses. J Exp Mar Biol Ecol 307:139-164

Pinder A, Friet S (1994) Oxygen transport in egg masses of the amphibians Rana sylvatica and Ambystoma maculatum: convection, diffusion and oxygen production by algae. J Exp Biol 197:17-30

Piñol J, Senar MA, Symondson WO (2019) The choice of universal primers and the characteristics of the species mixture determines when DNA metabarcoding can be quantitative. Mol Ecol 28:407-419

Printz A (1927) Chlorophyceae, in von Engler A, Prantl K (eds): Die natürlichen Pflanzenfamilien. vol 3. HR Engelmann: Leipzig

R-Core-Team (2019) R: a language and environment for statistical computing. Vienna: R Foundation for Statistical Computing. URL https://www.R-project.org/

Rognes T, Flouri T, Nichols B, Quince C, Mahé F (2016) VSEARCH: a versatile open source tool for metagenomics. PeerJ 4:e2584

Salthe SN (1963) The egg capsules in the Amphibia. J Morphol 113:161-171

Salthe S, Duellman W (1973) Quantitative constraints associated with reproductive mode in anurans. Columbia: Evolutionary Biology of the Anurans University of Missouri Press, 229-249

Schmeller DS, Blooi M, Martel A, Garner TW, Fisher MC, Azemar F, Clare FC, Leclerc C, Jäger L, Guevara-Nieto M (2014) Microscopic aquatic predators strongly affect infection dynamics of a globally emerged pathogen. Curr Biol 24:176-180

Schoenle A, Živaljić S, Prausse D, Voß J, Jakobsen K, Arndt H (2019) New phagotrophic euglenids from deep sea and surface waters of the Atlantic Ocean (Keelungia nitschei, Petalomonas acorensis, Ploeotia costaversata). Eur J Protistol 69:102-116

Small DP, Bishop CD (2020) Physiological benefits and latent effects of an algal-salamander symbiosis. Comp Biochem Physiol A Mol Integ Physiol 110715

Small DP, Bennett RS, Bishop CD (2014) The roles of oxygen and ammonia in the symbiotic relationship between the spotted salamander Ambystoma maculatum and the green alga Oophila amblystomatis during embryonic development. Symbiosis 64:1-10

Stamatakis A (2014) RAxML version 8: a tool for phylogenetic analysis and post-analysis of large phylogenies. Bioinformatics 30:1312-1313

Stoeck T, Bass D, Nebel M, Christen R, Jones MD, Breiner HW, Richards TA (2010) Multiple marker parallel tag environmental DNA 
sequencing reveals a highly complex eukaryotic community in marine anoxic water. Mol Ecol 19:21-31

Strathmann RR (2000) Form, function, and embryonic migration in large gelatinous egg masses of arenicolid worms. Invertebr Biol 119:319-328

Taberlet P, Bonin A, Coissac E, Zinger L (2018) Environmental DNA: For biodiversity research and monitoring. Oxford University Press

Tang CQ, Leasi F, Obertegger U, Kieneke A, Barraclough TG, Fontaneto D (2012) The widely used small subunit $18 \mathrm{~S}$ rDNA molecule greatly underestimates true diversity in biodiversity surveys of the meiofauna. Proc Natl Acad Sci USA 109:16208-16212

Tedersoo L, Anslan S, Bahram M, Põlme S, Riit T, Liiv I, Kõljalg U, Kisand V, Nilsson H, Hildebrand F, Bork P, Abarenkov K (2015) Shotgun metagenomes and multiple primer pair-barcode combinations of amplicons reveal biases in metabarcoding analyses of fungi. MycoKeys 10:1-43
Tsirogiannis C, Sandel B (2016) PhyloMeasures: a package for computing phylogenetic biodiversity measures and their statistical moments. Ecography 39:709-714

Wille N (1909) VII Abteilung Chlorophyceae Syllabus der Pflanzenfamilien Band 6 (Engler, A Eds). Berlin: Verlag von Gebrüder Borntraeger

Yassin E-KH, El-Said AAN (2011) Control of fish fungal pathogen Saprolegnia parasitica using rotifer Brachionus plicatilis and sodium chloride. Egypt J Exp Biol (Bot) 7:285-291

Zhang GK, Chain FJ, Abbott CL, Cristescu ME (2018) Metabarcoding using multiplexed markers increases species detection in complex zooplankton communities. Evol Appl 11:1901-1914

Publisher's Note Springer Nature remains neutral with regard to jurisdictional claims in published maps and institutional affiliations. 